\title{
Construção de ferramentas para estudo da possível interação entre interferon-beta e p53
}

\author{
Vinicius André Morais Rocha Melo
}

Dissertação apresentada ao Programa de Pós-Graduação Interunidades em Biotecnologia USP/Instituto Butantan/IPT, para obtenção do Título de Mestre em Biotecnologia. 


\title{
Construção de ferramentas para estudo da possível interação entre interferon-beta e p53
}

\author{
Vinicius André Morais Rocha Melo
}

Dissertação apresentada ao Programa de Pós-Graduação Interunidades em Biotecnologia USP/Instituto Butantan/IPT, para obtenção do Título de Mestre em Biotecnologia.

Área de Concentração: Biotecnologia

Orientador: Prof. Dr. Bryan Eric Strauss 
DADOS DE CATALOGAÇÃO NA PUBLICAÇÃO (CIP)

Serviço de Biblioteca e Informação Biomédica do Instituto de Ciências Biomédicas da Universidade de São Paulo

(c) reprodução total

\section{Melo, Vinicius André Morais Rocha.}

Construção de ferramentas para o estudo da possível interação entre interferon-beta e p53 / Vinicius André Morais Rocha Melo. - São Paulo, 2009.

Orientador: Bryan Eric Strauss.

Dissertação (Mestrado) - Universidade de São Paulo. Instituto de Ciências Biomédicas. Programa de Pós-Graduação Interunidades em Biotecnologia USP/IPT/Instituto Butantan. Área de concentração: Biotecnologia. Linha de pesquisa: Bases moleculares do câncer biomolecular.

Versão do título para o inglês: Construction of tools for study of the possible interaction between interferon-beta and p53.

Descritores: 1. Adenoviridae 2. Vírus 3. Expressão gênica 4. Neoplasias 5. Genes supressores I. Strauss, Bryan Eric II. Universidade de São Paulo. Instituto de Ciências Biomédicas. Programa de Pos-Graduação em Biotecnologia. III. Título. 
Candidato(a): $\quad$ Vinicius André Morais Rocha Melo

Título da Dissertação: Construção de ferramentas para estudo da possível interação entre interferon-beta e p53.

Orientador(a): $\quad$ Bryan Eric Strauss.

A Comissão Julgadora dos trabalhos de Defesa da Dissertação de Mestrado, em sessão pública realizada a , considerou
( ) Aprovado(a)
( ) Reprovado(a)

Examinador(a): Assinatura:.

Nome:

Instituição:

Examinador(a): Assinatura:.

Nome:

Instituição:

Presidente: Assinatura:...

Nome:

Instituição: 
Aos meus pais, minha família e meu orientador pelo incentivo e apoio constante, mas principalmente por terem acreditado em mim em diversos momentos da minha vida. 


\section{AGRADECIMENTOS}

Ao Dr. Bryan Eric Strauss, pela sua orientação constante, apoio e ensinamentos durante a execução deste trabalho, muito importantes para minha formação e desenvolvimento científico.

À minha equipe de trabalho do Setor de Vetores Virais - InCor: Márcio, Christian, Rafael, Paula, Carol e Daniela, pela ajuda, trocas de idéias e momentos de descontração.

Ao Dr. Márcio Chaim Bajgelman, pelos ensinamentos de várias técnicas de grande importância para o desenvolvimento deste trabalho.

À Dra. Eugenia Costanzi-Strauss por colaborar com diversas ferramentas, desenvolvidasvidas em seu laboratório, utilizadas neste trabalho.

À Dra. Juliana Colozzo Gregório, pelas "dicas" e grande ajuda para desenvolvimento deste projeto.

Ao Dr. José Eduardo Krieger, diretor do Laboratório de Genética e Cardiologia Molecular - INCOR FMUSP, por disponibilizar toda sua equipe e laboratório para as etapas principais do desenvolvimento deste trabalho.

Ao Dr. Roger Chammas, por disponibilizar o manuseio do citômetro de fluxo.

À FAPESP pelo apoio Financeiro.

A toda minha família, pelo grande apoio sendo este de inúmeras maneiras.

Aos meus amigos por todo incentivo e compreensão ao longo desses anos. 


\section{RESUMO}

MELO, V. A. M. R. Construção de ferramentas para estudo da possível interação entre interferon-beta e p53. Dissertação (Mestrado) - Instituto de Ciências Biomédicas, Universidade de São Paulo, São Paulo, 2008.

A formação de tumores se deve a uma combinação de fatores, incluindo alteração no controle de proliferação celular, alteração na sua resposta a sinais extracelulares e a tolerância da presença do tumor pelo sistema imune. A via de p53 representa um eixo fundamental no controle de proliferação e indução de apoptose. O interferon-beta (IFNß) tem um papel importante na modulação da resposta imunológica, participa na criação de memória imunológica antitumoral e também tem impacto na potência proliferativa e apoptótica de células tumorais. Recentemente, dados da literatura mostraram que IFN $\beta$ ativa transcrição de p53 e que vários componentes do sistema IFN efetuam sua função utilizando a via p53/p14arf. Neste projeto, construímos uma série de ferramentas a serem utilizadas, futuramente, para explorar as interações entre p53 e IFN $\beta$ num modelo de melanoma. A primeira ferramenta, uma linhagem celular derivada de B16 com expressão de p53 reduzida por meio de miRNA, será útil na medida da resposta a IFN $\beta$ quando a célula apresenta ou não a proteína p53. Este projeto também inclui a construção de vetores plasmidiais e adenovirais portadores dos cDNAs para eGFP, Luciferase, p53 ou IFN $\beta$ murino. Estes vetores são utilizados para a introdução destes fatores, sozinho ou em combinação, em células alvos para avaliação do seu impacto em expressão gênica, proliferação ou morte celular. Em ensaios preliminares, plasmídeos contendo o cDNA de luciferase dirigido por um promotor responsivo a p53 ou responsivo a componentes do sistema IFN foram co-transfectados em celulas B16 com os vetores de expressão para p53 e IFN $\beta$. Mesmo confirmando a atividade de p53 ou IFNß sozinho, não foi observado um efeito aditivo destes fatores utilizando este tipo de ensaio. Futuros estudos sobre possíveis interações entre as vias de p53 e IFN $\beta$ terão o benefício das ferramentas construídas neste projeto.

Palavras-chave: p53. Interferon. Melanoma. 


\begin{abstract}
MELO, V. A. M. R. Construction of tools for study of the possible interaction between interferon-beta and p53. Master thesis - Instituto de Ciências Biomédicas, Universidade de São Paulo, São Paulo, 2008.
\end{abstract}

The formation of tumors is related to a combination of factors, including alteration in the control of cellular proliferation, alteration in response to extra cellular signals and tolerance of the tumor's presence by the immune system. The p53 pathway represents a fundamental axis for the control of proliferation and induction of apoptosis. Interferon-beta (IFN $\beta$ ) plays an important role in the modulation of immune response, participates in the creation of anti-tumor immunologic memory and also impacts the proliferative and apoptotic potential of tumor cells. Recently, data from the literature has shown that IFN $\beta$ activates transcription of p53 and that some components of IFN system exert their function through the p53/p14arf pathway. In this project, we constructed a series of tools to be used to explore the interactions between p53 and IFN $\beta$ in a melanoma model. The first tool, a derivative of the B16 cell line with reduced p53 expression due to a specific miRNA, will be useful for the measurement of the IFN $\beta$ response in presence or absence of cellular p53 protein. This project also includes the confirmation of plasmid and adenoviral vectors that carry the cDNAs of eGFP, Luciferase, p53 or murine IFN $\beta$. These vectors can be used for the introduction of these factors, alone or in combination, in target cells for evaluation of their impact on gene expression, proliferation or cell death. In preliminary assays, plasmids encoding the Luciferase cDNA with expression directed by a p53-responsive promoter or a promoter responsive to components of IFN system were co-transfected in B16 cells with the p53 and IFN $\beta$ expression vectors. Even though the activity of either p53 or IFN $\beta$ alone was confirmed, an additive effect of these factors was not observed using this assay. Future studies of the possible interactions between the p53 and IFN $\beta$ pathways will benefit from the tools constructed in this project.

Keywords: p53. Interferon. Melanoma. 


\section{LISTA DE ILUSTRAÇÕES}

Figura 1. Esquema da sinalização do sistema IFNa/ß....................................18

Figura 2. Representação esquemática do mecanismo de indução por IFNa/ß..19

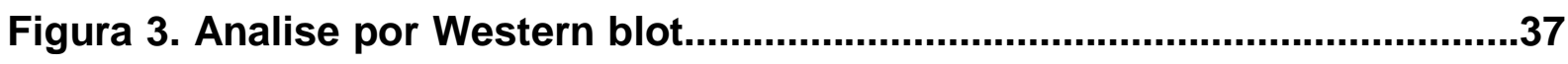

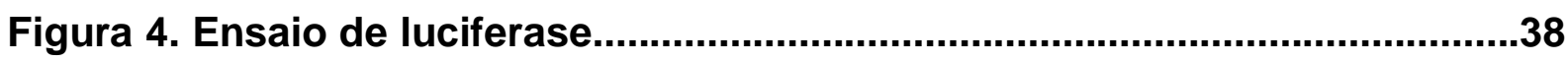

Figura 5. Quadro esquemático da tecnologia Gateway........................................39

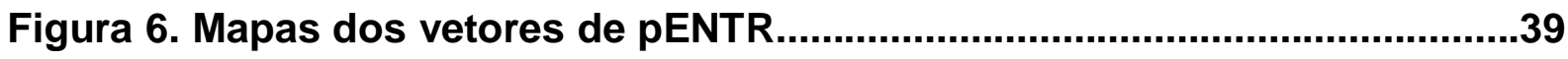

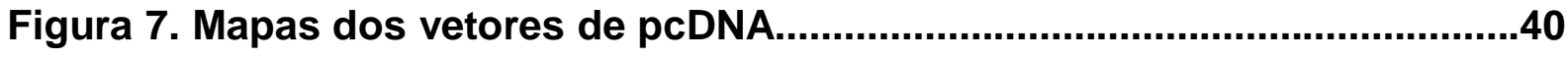

Figura 8. Analise de expressão de GFP do vetor pcDNAeGFP...........................41

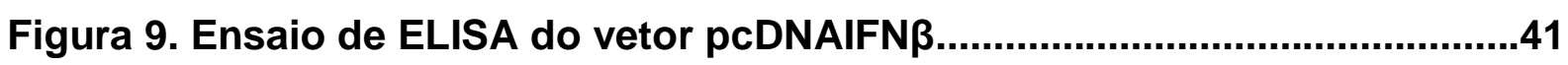

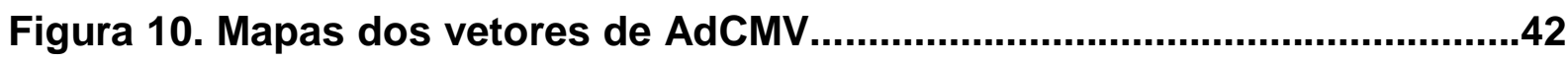

Figura 11. Analise de expressão de GFP do vetor AdCMVeGFP........................42

Figura 12. Analise de luciferase com vetores repórter......................................44 


\section{LISTA DE TABELAS}

Tabela 1. Quantidades de DNA utilizada na transfecção.....................................34 


\section{LISTA DE ABREVIATURAS}

CAR coxsackie-adenovirus receptor

CAT Chloramphenicol acetyl-transferase

CMV citomegalovírus

DMEM Dulbecco's Modified Eagle Medium

DNA ácido desoxirribonucléico

FACS citômetro de fluxo

G418 geneticina

GFP proteína fluorescente verde

HBS-2x solução salina tamponada com HEPES, concentrada duas vezes

HSP heat shock protein

IFN Interferon

IRF interferon regulatory factor

ISRE interferon stimulated response element

ITR inverted terminal repeats

$\mathrm{Kb} \quad$ kilo base

Mdm2 mouse double minute 2

MDR1 multidrug resistance gene

Min minuto

MOI multiplicity of infection

MPC monocyte chemotactic protein

Neo resistência a neomicina

NK células natural killer

$\mathrm{Pb} \quad$ pares de base

PBS-1x solução salina tamponada com fosfato, concentrada uma vez

RGC ribossomal gene cluster

RNA ácido ribonucléico

RPM rotações por minuto

SV40 Simian Virus 40

TNF tumor necrosis factor

TR enzima transcriptase reversa

UV ultra violeta

VSV-G proteína $\mathrm{G}$ do vírus da estomatite vesicular 
tipo selvagem 


\section{SUMÁRIO}

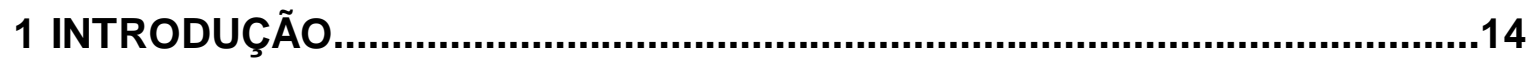

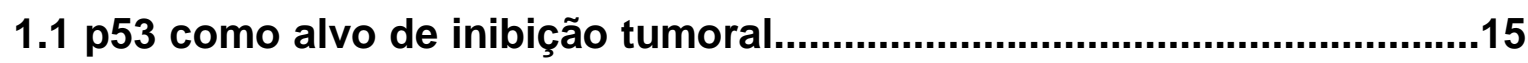

1.2 Interferon-beta (INF $\beta$ ): gene candidato para terapia gênica de melanoma

1.3 Interação entre p53 e IFN $\beta$ : possível beneficio para o tratamento de câncer.

1.4 Desenvolvimento de vetores adenovirais para transferência gênica......22

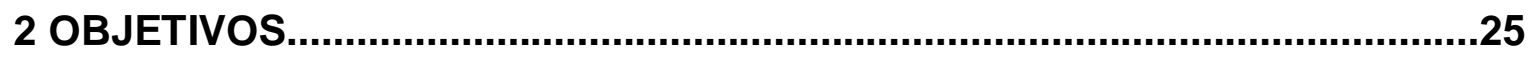

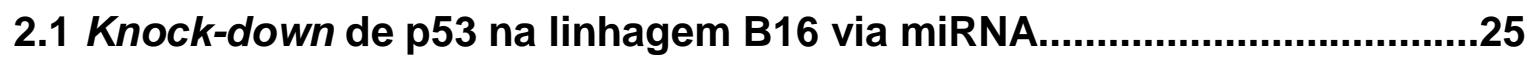

2.2 Construção e caracterização de vetores plasmidiais (pcDNA3)

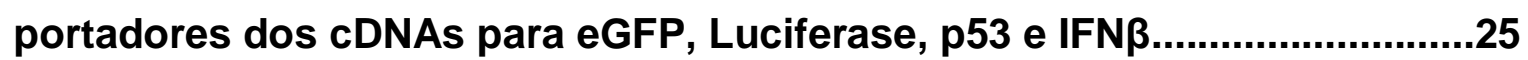

2.3 Construção e caracterização de vetores adenovirais (AdCMV) portadores dos cDNAs para eGFP, Luciferase, p53 e IFN $\beta$...........................25

2.4 Ensaios para explorar possíveis interações entre as vias de p53 e IFN $\beta$, incluindo ensaios repórter e de ciclo celular.................................................25

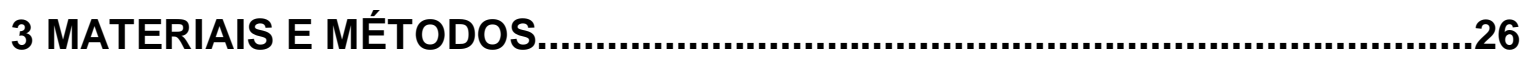

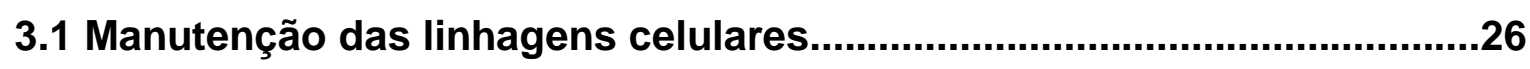

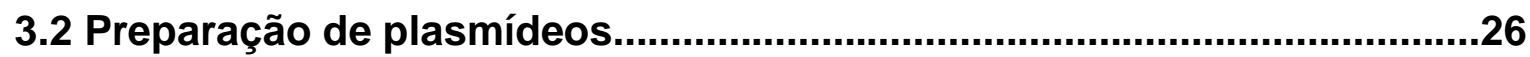

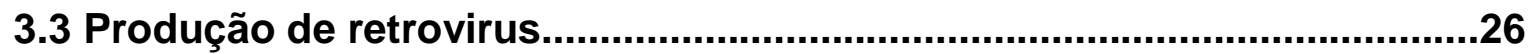

3.4 Transdução e seleção de B16 para produção de linhagem RNAi-p53.....27

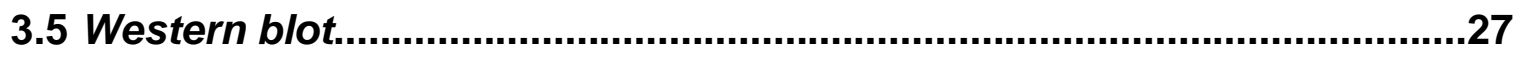

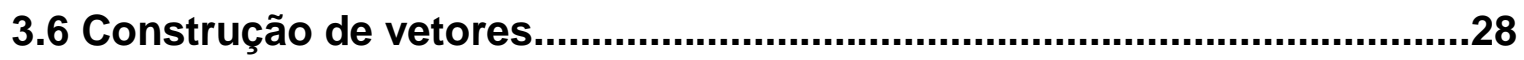

3.6.1 Construção dos vetores pENTR

3.6.2 Montagem dos vetores plasmidias via recombinação homóloga..........30

3.6.3 Montagem dos vetores adenovirais via recombinação homóloga........30

3.7 Produção inicial de preparações adenovirais...........................................31

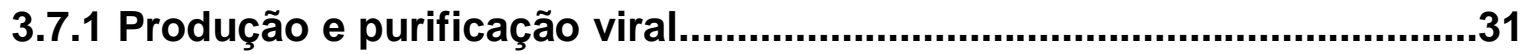

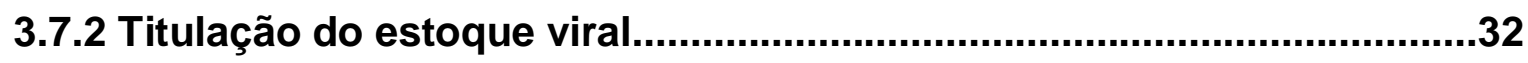

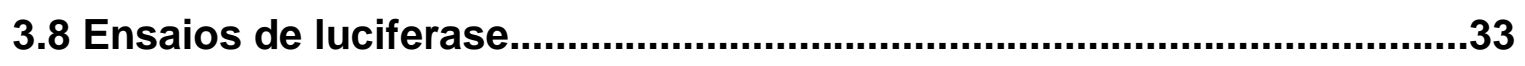

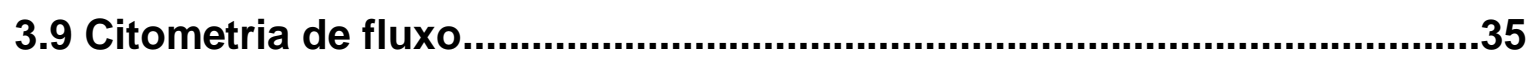

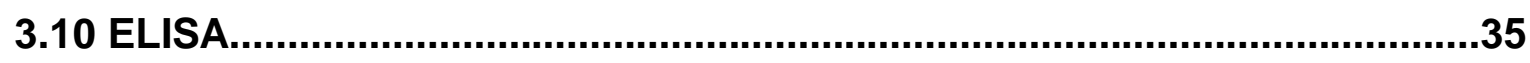

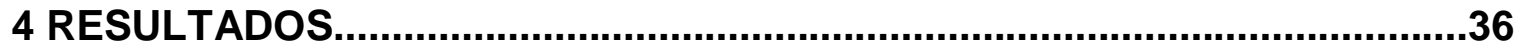


4.1 Knock-down de p53 na linhagem B16 via miRNA......................................

4.2 Construção e caracterização de vetores plasmidiais (pcDNA3) portadores dos cDNAs para eGFP, Luciferase, p53 e IFN $\beta$.

4.3 Construção e caracterização de vetores adenovirais (AdCMV) portadores dos cDNAs para eGFP, Luciferase, p53 e IFN $\beta$.

4.4 Ensaios para explorar possíveis interações entre as vias de p53 e IFN $\beta$, incluindo ensaios repórter e de ciclo celular. .43

5 DISCUSSÃO. .45

6 CONCLUSÃO. .51

6.1 Knock-down de p53 na linhagem B16 via Mirna

6.2 Construção e caracterização de vetores plasmidiais (pcDNA3) portadores dos CDNAs para eGFP, Luciferase, p53 e IFN $\beta$.

6.3 Construção e caracterização de vetores adenovirais (AdCMV) portadores dos CDNAs para eGFP, Luciferase, p53 e IFN $\beta$.

6.4 Ensaios para explorar possíveis interações entre as vias de p53 e IFN $\beta$, incluindo ensaios repórter e de ciclo celular 



\section{INTRODUÇÃO}

Melanoma é um tipo de câncer que atinge o tecido epitelial, mais especificamente a pele, podendo ser do tipo benigno ou maligno. O melanoma origina-se dos melanócitos (células produtoras de melanina). A transformação oncogênica dos melanócitos epidermais dão origem ao melanoma cutâneo primário. Embora apresente uma incidência de $3 \%$ a $7 \%$ dos casos de carcinomas da pele, o melanoma é o tipo mais grave da doença devido a sua alta probabilidade de metástase (GIGLIA-MARI e SARASIN, 2003; LENS e DAWES, 2004).

Até agora não há uma terapia adequada para controle ou cura do melanoma tanto na sua forma primária como em metástases. Nas últimas décadas, a incidência de melanoma vem crescendo mundialmente e a mortalidade pela doença permanece alta. Embora a maioria dos melanomas primários seja curável por excisão cirúrgica, a expectativa de vida cai dramaticamente, abaixo dos $3 \%$, quando há ocorrência de metástase (EBERLE et al., 2008). O uso de uma terapia que agregue o combate ao melanoma primário e a possíveis metástases levaria a um aumento significante da sobrevida dos pacientes. Por isso a utilização da resposta imunológica mediada por IFN $\beta$ no tratamento, já que uma de suas funções é a ativação da resposta adaptativa do sistema imune, podendo assim inibir formação de metástases posteriores.

Atingir a via de p53 no tratamento de melanoma talvez fosse interessante já que o p53 é um dos genes supressores de tumor mais comumente mutado em neoplasias (HOLLSTEIN et al., 1994). Normalmente, há pouca proteína p53 na célula, mas em resposta a vários fatores, como dano por UV, altos níveis de p53 são induzidos. Com os altos níveis da proteína p53 ocorre uma parada em G1 do ciclo celular, permitindo à via de reparação celular remover as lesões causadas antes da síntese de DNA e mitose, e promove também um aumento da apoptose. Em melanoma, somente $10 \%$ dos casos apresentatam p53 mutado (GIGLIA-MARI e SARASIN, 2003). No entanto, mesmo que as células de melanoma apresentem p53 endógeno, este está inativo (LANE, 1992; LEVINE, 1997; BENJAMIN e ANANTHASWAMY, 2007). Tratar as células de melanoma repondo o p53 na sua forma normal não foi satisfatório em nossos estudos (Setor de Vetores Virais, dados não publicados). Alternativamente, aproveitando-se do fato de que o melanoma 
apresenta p53, outra estratégia seria utilizar radiação, uma droga ou outro gene que ative o p53 endógeno. Dados da literatura indicam que IFN $\beta$ exerça sua função, em parte, através da via de p53 (TAKAOKA et al., 2003). Por estes motivos, temos interesse em explorar as possíveis interações entre IFN $\beta$ e p53.

\section{1 p53 como alvo de inibição tumoral}

Em protocolos clínicos de terapia gênica, o gene p53 foi utilizado como gene terapêutico em 69 protocolos, mas nenhum para melanoma (http://www.wiley.co.uk/genmed/clinical/). Como descrito a seguir, p53 é um candidato para o tratamento de câncer devido ao seu papel central em controle de proliferação e indução de morte celular. Isto se deve ao fato da proteína p53 ser fator transcricional de vários genes ligados ao ciclo celular (tais como p21 (WAF1), 14-3-3, GADD45 e B99), genes pró-apoptóticos (Bax, Fas/APO1, Killer/DR5, PIGs, p85, PAG608, IGF-Bp3) e genes ligados à inibição da angiogênese (Tsp1, BAl1, GDAiF) (EL-DEIRY, 1998). A p53 age também como inibidora de transcrição de uma variedade de promotores, incluindo genes que bloqueiam apoptose, como $\mathrm{Bcl}-2$ (MIYASHITA et al., 1994), e genes que proporcionam resistência a drogas quimioterápicas, como o multidrug resistance gene, MDR1 (STRAUSS et al., 1995).

A p53 age como indutor de transcrição se ligando diretamente no promotor de seus genes alvos. Um dos primeiros elementos responsivos a p53 identificados foi isolado do RGC (Ribossomal Gene Cluster) (KERN et al., 1991). Na seqüência repórter PG13-CAT, 13 cópias do elemento PG (derivado do RGC) foram unidas a um promotor mínimo e ao cDNA da cloranfenicol acetil transferase (CAT), resultando uma unidade regulatória muito sensível a p53 (KERN et al., 1992). A seqüência geral reconhecida pela p53, PuPuPuCA/TA/TGPiPiPi (onde $\mathrm{Pu}=$ purina e $\mathrm{Pi}=$ pirimidina) foi definida logo depois (EL-DEIRY et al., 1992; FUNK et al., 1992) e está presente no promotor de todos os genes ativados por p53.

Mutações no gene p53 são as alterações mais comuns de câncer humano (HOLLSTEIN et al., 1994). Em geral, p53 mutado perde sua função como fator de transcrição, mas em alguns casos, a proteína mutada pode ganhar novas funções, como promoção de proliferação celular ou ativação de genes não desejados 
(DITTMER et al., 1993; HSIAO et al., 1994; STRAUSS e HAAS, 1995). A perda da atividade de p53 deixa a célula vulnerável à proliferação não controlada e relativamente resistente para apoptose induzida por quimioterápicos ou radiação (LOWE e RULEY, 1993; LOWE et al., 1993a; LOWE et al., 1993b). Por estes motivos, a reposição de p53 como alvo terapêutico continua como uma nova esperança no tratamento do câncer.

Mutações no gene de p53 foram detectadas em 50\% dos cânceres humanos e em quase todos os carcinomas de pele. A maioria dos carcinomas possui mutações onde ocorre a alteração de um aminoácido produzindo a proteína completa, porem, com sua função alterada. Análise de mutações no gene p53 estabeleceram uma conexão entre exposições a radiações ultra violeta(UV), dano ao DNA e carcinogênese de pele, e outros trabalhos já mostraram que p53 tem um importante papel na proteção celular contra danos ao DNA causados por exposição a UV (Zahn et al., 1993; BENJAMIN e ANANTHASWAMY, 2007). Porém, no caso de melanoma, p53 se encontra mutado em somente 10\% dos casos (GIGLIA-MARI e SARASIN, 2003). Em contraste, o locus CDKN2a onde reside o gene do p14ARF (humano) é perdido em 50\% dos casos de melanoma (SHARPLESS e CHIN, 2003).

Melanoma é um dentre outros tipos tumorais onde p53 mantêm-se selvagem, indicando que outros eventos contribuem para inativação de p53. p53 é mantido inativo e a baixos níveis predominantemente pelo produto do gene mdm2, que se liga diretamente a p53 e a degrada por um mecanismo de ubiquitinação. A expressão de mdm2 por sua vez é regulada pelo próprio p53 através de feedback negativo. Apesar de p53 se manter selvagem, na maioria dos casos de melanoma, o mdm2, regulador negativo de p53, apresenta-se super-expresso em grande parte dos casos de melanoma inibindo a função de p53. Enquanto isso a perda da expressão protéica de p14arf, que inibe a ação de mdm2, ocorre em 50-70\% dos melanomas com alta capacidade de proliferação. Em estudos recentes foi mostrado que p19arf possui um importante papel antitumoral (HA et al., 2008; BOX e TERZIAN, 2008).

Nas células tumorais, a inativação do p53 primariamente ocorre por mutações no p53, super-expressão dos seus inibidores, como o mdm2, e perda ou inativação dos seus ativadores como o p14arf (p19arf em camundongos). Diferentes combinações de eventos que promovam a redução ou inibam os níveis e atividade de p53 selvagem levam a perda de apoptose, proliferação descontrolada e 
transformação celular. Transformações malignas sempre envolvem a desregulação de pontos restritos do ciclo celular, no entanto, eventos adicionais são necessários para o surgimento de um fenótipo maligno, devido ao fato que sinais hiperproliferativos ativam um mecanismo de defesa que resulta na parada do ciclo celular, senescencia ou apoptose. O maior efetor desse mecanismo é a via ARFMDM2-p53. Sendo que a célula de melanoma possui p53 endógeno, a utilização de ARF, ao invés de p53, na terapia gênica poderia ser melhor explorado, visto que a ativação de ARF inibe a interação de MDM2 com p53, permitindo que p53 promova a parada da progressão celular e induza apoptose ou senescência (SANDOVAL et al., 2004; HA et al., 2008; BOX e TERZIAN, 2008).

\subsection{Interferon-beta (INF $\beta$ ): gene candidato para terapia gênica de melanoma}

Interferons (IFNs) são proteínas multifuncionais secretadas envolvidas na defesa antiviral, regulação do ciclo celular e ativação de imunidade. IFNs fazem parte da família das citocinas com efeitos biológicos pleiotrópicos (CHAWLASARKAR et al., 2003). Classificam-se como $\alpha, \beta, \omega, \gamma$, de acordo com suas bases estruturais e propriedades antigênicas, e são agrupadas em duas famílias: Tipo I e Tipo II. IFN $\alpha, \beta$ e $\omega$ pertencem à família do Tipo I e são produzidas pela maioria dos tipos celulares em resposta a infecção viral ou outro estímulo. IFNy, o único que pertence à família Tipo II, é secretado por linfócitos T e células NK em resposta a mitógenos ou antígenos específicos (PORTA et al., 2005).

A atividade do sistema IFN Tipo I pode causar morte celular e necessita de controle preciso para evitar sua ativação inapropriada. Na ausência de infecção viral, células produzem pouco IFN $\beta$ e, então, IFN $\beta$ não esta ligada no seu receptor e não ativa o sistema Jak-STAT. Na fase precoce após infecção viral, o IRF-3 (interferon regulatory factor-3) é modificado por fosforilação e torna ativo induzindo expressão de IFN $\beta$. Agora que IFN $\beta$ está presente, ele se liga ao seu receptor (Type-I interferon receptor, IFNAR), inicia a transdução de sinal mediado pelo sistema Jak-STAT, e torna ativo o complexo ISGF3 (contendo stat-1 e stat-2 fosforilados e IRF-9). Por sua vez, ISGF3 ativa transcrição via elemento ISRE (interferon stimulated response element) presente no promotor de IRF-7. Na fase tardia apos infecção viral, indução forte de IRF-7 fosforilado coopera com IRF-3 fosforilado e ativa transcricionalmente 
os genes de IFNa/ $\beta$. Junto, IFN $\beta$ e IFNa ligam-se ao seu receptor e fortalecem o sistema de ativação de IFN via um mecanismo de feedback positivo. A ativação do sistema IFN resulta na expressão dos fatores mencionados acima e também a expressão de $\mathrm{MHC}$, citocinas e fatores quimiotáticos. A soma destes fatores pode ativar o sistema imune via células T-CD4, T-CD8, maturação de células dendríticas, atração de macrófagos e indução de apoptose (SATO et al., 2001). IFNs podem mediar efeitos antitumorais tanto indiretamente por imunomodulação e respostas anti-angiogênicas como diretamente afetando a proliferação ou diferenciação de células tumorais (CHAWLA-SARKAR et al., 2003).

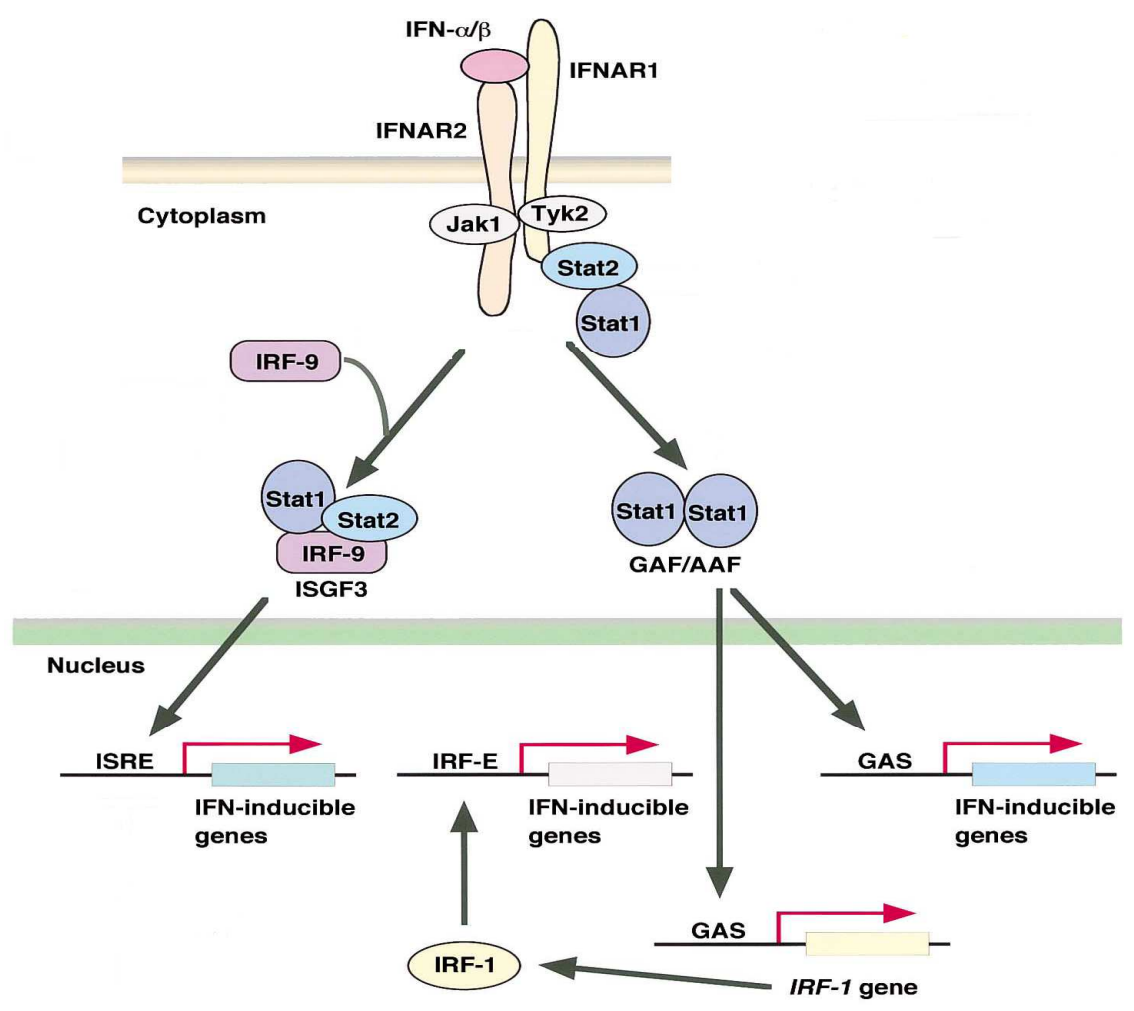

Figura 1: Esquema da sinalização de trandução e regulação transcricional do sistema de IFNa/ $\beta$ (SATO et al., 2001). 


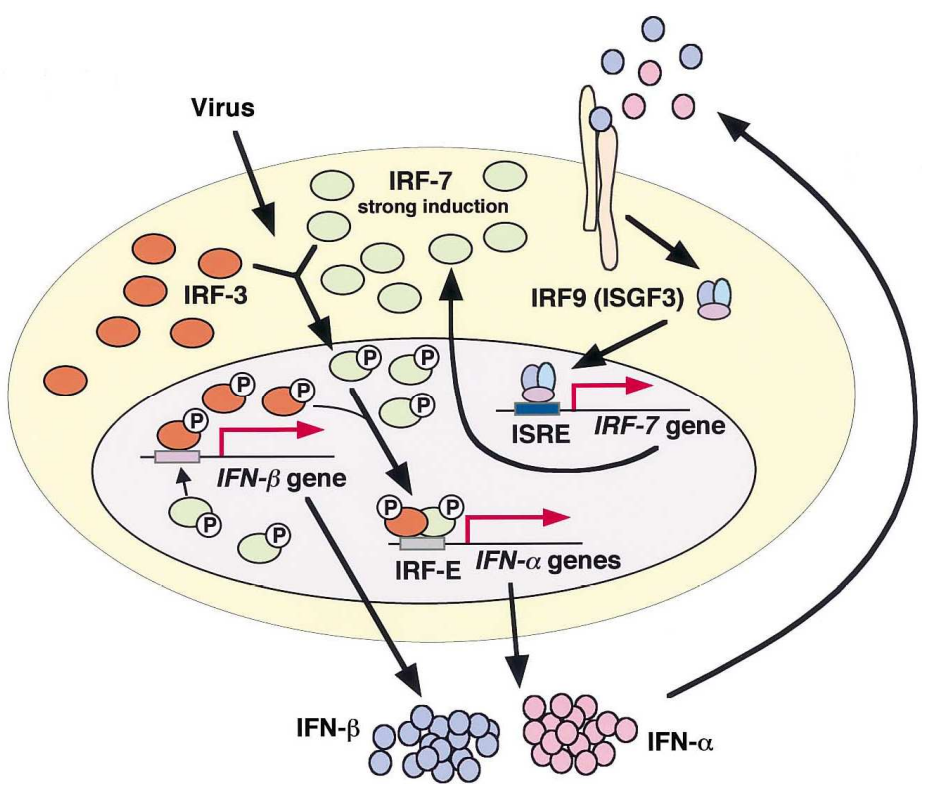

Figura 2: Representação esquemática do mecanismo de indução genica por IFNa/ß (SATO et al., 2001).

No começo dos anos de 1969, foi mostrada que IFNs também apresentavam uma atividade antitumoral (DE PALMA et al., 2008). Proteínas recombinantes de IFN- $\alpha / \beta$ são usadas para o tratamento de algumas formas de câncer (SATO et al., 2001; YOSHIDA et al., 2004). IFN é considerado um fator importante na formação de glioma e melanoma devido à deleção freqüente do lócus contendo o grupo de genes de IFN em tumores humanos (MIYAKOSHI et al., 1990; JAMES et al., 1991). IFNs foram as primeiras proteínas humanas com ação afetiva na terapia de câncer e está entre os primeiros produtos de DNA recombinante a ser usado clinicamente (CHAWLA-SARKAR et al., 2003). Nos anos de 1980, a proteína IFN $\beta$ foi usada clinicamente, no Japão, como uma droga anti-câncer e mostrou um claro efeito inibitório no crescimento de glioma e melanoma malignos (YOSHIDA et al., 2004). Atualmente, IFN recombinante é freqüentemente utilizado como terapia coadjuvante de melanoma, mas este tratamento é limitado pela curta meia-vida da proteína e 
toxicidade associada com altas doses (SABEL e SONDAK, 2003; KAVANAGH et al., 2005).

Uma alternativa para tratamento de câncer com IFNß seria a terapia gênica. Pelo menos seis protocolos clínicos de terapia gênica do câncer foram abordados utilizando IFNß como gene terapêutico (http://www.wiley.co.uk/genmed/clinical/). A transferência do gene de IFN $\beta$ diretamente para células tumorais deverá oferecer um efeito localizado e evitar toxicidade pela proteína recombinante de IFN $\beta$. Ensaios mostraram que células resistentes ao tratamento com proteína recombinante foram sensíveis a tratamento gênico com IFNß. Em um protocolo desenvolvido por Yoshida et al. (2004), eles testaram a segurança e efetividade de usar terapia gênica de IFN $\beta$ em pacientes. A proteína IFN $\beta$ produzida pelo gene foi detectada nos pacientes assim como outras citocinas próinflamatórias, sugerindo a ativação de outras vias para o controle do tumor. Yoshida et al. comenta que o estudo demonstra segurança e aplicabilidade na terapia gênica de interferon- $\beta$ em tumores agressivos que resistam a tratamentos assim como melanomas malignos (YOSHIDA et al., 2004).

Outros protocolos relacionados ao teste de segurança e aplicabilidade da terapia gênica com IFN $\beta$ também detectaram a proteína IFN $\beta$ dentro e ao redor do tumor, assim como a presença de processos inflamatórios e ativação do sistema imune. Esses estudos também observaram indução de apoptose, ação antiangiogênica, ativação do interferon endógeno e devido a esses fatores, uma redução significativa do tumor. Baseado nos resultados obtidos nesses trabalhos, as descobertas sugerem que o uso da terapia gênica de IFN $\beta$ pode ser segura e eficaz mesmo em pacientes que não responderam positivamente a um tratamento primário (STERMAN et al., 2007; WAKABAYASHI et al., 2008; CHIOCCA et al., 2008).

Ensaios laboratoriais demonstram a capacidade de IFN $\beta$ em inibição tumoral e indução de memória imunológica. Por exemplo, um modelo experimental de fibrosarcoma foi tratado com adenovirus portador de IFN $\beta$, como resultado o tumor primário foi abolido. A re-implantação de células tumorais em animais previamente curados não resultou em formação de nenhum tumor, indicando a indução de imunidade contra este tipo celular (LU et al., 1999). Em conjunto com apoptose, células de glioma transduzidas pelo gene de IFN $\beta$, produzem interleucinas (IL)-1 $\beta$, IL-6, TNF (tumor necrosis factor), MPC-1 (monocyte chemotactic protein), IFNYinducible protein-10 (IP-10) e HSP (heat shock protein), além da IFN $\beta$. A transferência gênica de IFN $\beta$ ativa as respostas do sistema imune e facilita a imuno- 
infiltração celular (YOSHIDA et al., 2004). Utilizando um modelo de melanoma com células B16 no camundongo C57BL/6, a metástase foi reduzida com tratamento gênico diretamente nos tumores primários ou com injeção sistêmica com um adenovirus (ALIZADEH et al., 2003). Claramente, a noção de empregar IFN $\beta$ como gene terapêutico esta ganhando favor.

\subsection{Interação entre p53 e IFNß: possível beneficio para o tratamento de câncer}

Recentemente, dados da literatura indicaram que existe interações funcionais entre as vias de p53 e IFN. Células tratadas com proteína recombinante IFNa ou IFNß respondem com um aumento no nível de proteína p53. Um elemento ISRE, responsivo a ISGF3, foi identificado no promotor do gene de p53. Então, a indução de p53 por IFNß é causada por ativação transcricional (TAKAOKA et al., 2003). Este caso é extremamente interessante devido ao fato que ativação de p53 ser tipicamente associado com modificação pós-tradução, mas não com aumento de sua transcrição (LEVINE, 1997). Sobretudo, foi demonstrado que apoptose de células tumorais com tratamento com proteína recombinante IFNa ou IFN $\beta$ foi aumentado na presença de p53 (TAKAOKA et al., 2003). Então, o efeito pró-apoptótico de IFN envolve p53.

Em algumas linhagens celulares, o efeito citostático dos IFNs tipo I não requer p14ARF (o parceiro funcional de p53) ou p53; em outras linhagens celulares, a indução de apoptose requer p14ARF (mas não p53) (SANDOVAL et al., 2004). Também, p53 ativa diretamente a expressão de IRF-5 (MORI et al., 2002), mas a função de IRF-5, um candidato supressor de tumor, não depende de p53 (HU et al., 2005).

Com este projeto, pretendemos avaliar o papel de p53 no efeito antitumoral de IFN $\beta$. Muito pouco é conhecido sobre as interações do sistema IFN com p53, sendo assim, gostaríamos de elucidar mais informações com respeito à ativação do sistema IFN e ativação de genes alvos de p53. Também, procuraremos o efeito funcional de IFN $\beta$ mais p53, avaliando proliferação e morte celular. Com o sucesso 
deste projeto, teríamos os primeiros dados sugerindo que a combinação de p53 mais IFNß poderia ser uma estratégia interessante para inibição de câncer.

\subsection{Desenvolvimento de vetores adenovirais para transferência gênica}

Protocolos clínicos de terapia gênica têm sido abordados durante os últimos 18 anos, predominantemente nos Estados Unidos e na Europa. Durante esta experiência, 337 protocolos foram elaborados utilizando adenovirus como vetor de transferência gênica, sendo 258 destes direcionados para tratamento de câncer e, especificamente, dois protocolos para 0 tratamento de melanoma (http://www.wiley.co.uk/genmed/clinical/).

Vários são os motivos para se utilizar vetores recombinantes derivados do adenovirus $(\mathrm{Ad})$ como vetor de transferência gênica: ele pode gerar grandes títulos in vitro (em torno de $10 \times 10^{12}$ partículas por $\mathrm{mL}$ ), o que facilita sua utilização clínica; pode transduzir uma grande variedade de células de mamíferos; transduz células mitóticas e pós-mitóticas; baixa patogenicidade para humanos; possui uma grande fita dupla de DNA (suportando grandes inserções de até 7,5 kb); não integra seu DNA ao da célula hospedeira, não havendo risco de ativação ou inativação aleatória de genes; possui um forte tropismo por células cancerosas, tornando-o assim um ótimo vetor para a terapia gênica de câncer (Roy-Chowdhury e Horwitz, 2002; Russell, 2000).

Os adenovirus possuem um genoma de DNA linear com fita dupla, de tamanhos que variam entre 30 e $40 \mathrm{~kb}$, sendo que o Ad5 possui 35.935 pb. Este genoma é flanqueado em suas extremidades direita e esquerda por ITRs (inverted terminal repeats) que funcionam como origem de replicação. Próximo ao ITR esquerdo está o sinal de empacotamento, necessário para a internalização do genoma no capsídeo. As outras partes do genoma são divididas de acordo com a ordem de expressão no ciclo de infecção, sendo os expressos na fase inicial antes da replicação do DNA viral chamados de $E$ e os na fase posterior de L (ROYCHOWDHURY e HORWITZ, 2002; RUSSELL, 2000). 
Os genes $\mathrm{E}$ codificam proteínas que regulam a replicação viral, e são classificados de 1 a 4 . A primeira região transcrita durante a infecção viral é a $E 1 A$, grande responsável pela replicação viral e regulação da transcrição. Em seguida, a região $\mathrm{E} 1 \mathrm{~B}$ produz proteínas que bloqueiam o mRNA do hospedeiro e estimula 0 transporte do mRNA adenoviral do núcleo para o citoplasma (ROY-CHOWDHURY e HORWITZ, 2002; RUSSELL, 2000).

Os genes L, que iniciam sua transcrição depois da replicação do DNA viral, são responsáveis pela estrutura protéica da partícula viral. Dentre estas proteínas estão às responsáveis pelo reconhecimento entre o vírus e a célula. Proteínas virais chamadas knob se ligam ao receptor CAR (coxsackie-adenovirus receptor) na membrana celular, ativando assim outras proteínas de membrana chamadas integrinas $\alpha_{v} \beta$ que interagem com o penton base e possibilitam a internalização do vírus. Esta partícula viral entra na célula dentro de um endossomo que posteriormente é lisado pela ação de proteínas do envoltório viral, liberando o vírus no citosol. O genoma do vírus é então liberado no núcleo onde passa a transcrever, replicar e empacotar as novas partículas virais (ROY-CHOWDHURY e HORWITZ, 2002; RUSSELL, 2000).

No entanto, vetores adenovirais recombinantes possuem deleções da região E1A e de parte da E1B. Tipicamente, estes vetores apresentam a região E1 deletada do nt 1 ao 3533 e também deleções na região E3, uma vez que esta região não é essencial para a produção em cultura e é a responsável por gerar grande parte da resposta imune de células infectadas. A maneira usada para a produção de vírus utiliza uma estratégia de amplificação do estoque viral. Este processo começa com a transfecção da construção adenoviral em células que possuam E1. As células utilizadas em nosso laboratório são células embrionárias de rim humano (HEK293) que produzem E1, complementando vetores deletados nessa região. Assim, Ad produzidos em HEK293 podem infectar outras células, mas não podem replicar se essas células não expressam E1. Os vírus derivados desta primeira etapa têm um titulo baixo, mas servem como semente para sua amplificação. Este estoque é utilizado para infectar células HEK293, permitindo sua replicação com uma eficiência maior. Repetindo este processo permite um aumento no titulo e no volume de células utilizadas para produção do Ad (ROY-CHOWDHURY e HORWITZ, 2002; RUSSELL, 2000). 
Vírus oncolíticos, que podem replicar seletivamente e lisar as células tumorais com o mínimo de infecção/replicação em tecidos não neoplásicos, vem sendo desenvolvidas como uma inovação na terapia de câncer. A primeira terapia de câncer, utilizando vírus oncolítico, realizada no mundo foi aprovada na China no ano de 2005. Os dados mostraram que o vírus é bem tolera e tem uma boa eficácia quando combinado com outra terapia (como a quimioterapia) em alguns tratamentos para câncer (REN et al., 2008).

Existem ainda, alguns problemas em se utilizar Ad, principalmente no que diz respeito a esse controle de replicação. É possível que ocorram Ad replicativocompetentes em uma população de Ad replicativo-deficientes. Isso pode ocorrer como resultado de um duplo crossover entre seqüencias homólogas presentes no Ad recombinante e o genoma da célula HEK293, devolvendo ao vetor adenoviral a seqüência $E 1$, que o tornaria replicante novamente. Outro problema que pode ser enfrentado na utilização de Ad é uma significativa resposta imune quando utilizado in vivo, podendo gerar inflamação. Também existe a possibilidade do organismo infectado produzir anticorpos anti-Ad reduzindo a eficiência da transferência (ROYCHOWDHURY e HORWITZ, 2002; RUSSELL, 2000). 


\section{OBJETIVOS}

Neste projeto, planejamos a construção de ferramentas para introduzir e expressar os cDNAs de p53 e IFN $\beta$ em células de melanoma de camundongo, B16. Futuramente, pretendemos explorar as interações de IFN $\beta$ com a via p53/ARF e, talvez, desenvolver novas estratégias de terapia gênica de melanoma.

2.1 Knock-down de p53 na linhagem B16 via miRNA

2.2 Construção e caracterização de vetores plasmidiais (pcDNA3) portadores dos cDNAs para eGFP, Luciferase, p53 e IFN $\beta$

2.3 Construção e caracterização de vetores adenovirais (AdCMV) portadores dos cDNAs para eGFP, Luciferase, p53 e IFN $\beta$

2.4 Ensaios para explorar possíveis interações entre as vias de p53 e IFN $\beta$, incluindo ensaios repórter e de ciclo celular 


\section{MATERIAIS E MÉTODOS}

\subsection{Manutenção das linhagens celulares}

As linhagens HEK293 e 293T, ambas derivadas de células de rim embrionário humano (linhagens produtoras de adenovírus e retrovírus respectivamente) e $\mathrm{NIH}$ 3T3 derivada de fibroblasto de camundongo foram mantidas em meio DMEM (Dulbecco's Modified Eagle Medium, GIBCO-BRL, Grand Island, NY, USA) suplementado com 10\% de soro de bezerro (BCS, bovine calf serum, Hyclone, Logan Utah, USA), $100 \mu \mathrm{g} / \mathrm{mL}$ de gentamicina, $50 \mu \mathrm{g} / \mathrm{mL}$ de ampicilina e 2,5 $\mu \mathrm{g} / \mathrm{mL}$ de Fungizona (anfotericina B). As linhagem B16F10 (melanoma murino) e B16mCAR (clone derivado de da linhagem B16F10, contendo o receptor de membrana mCAR) foram mantidas em meio RPMI (RMPI-1640 GIBCO-BRL Grand Island, NY, USA) suplementado com 10\% de soro de bezerro (BCS, bovine calf serum, Hyclone, Logan Utah, USA), $100 \mu \mathrm{g} / \mathrm{mL}$ de gentamicina, $50 \mu \mathrm{g} / \mathrm{mL}$ de ampicilina e 2,5 $\mu \mathrm{g} / \mathrm{mL}$ de Fungizona (anfotericina B). Todas as linhagens foram mantidas a $37^{\circ} \mathrm{C}$ em atmosfera úmida com $5 \%$ de $\mathrm{CO}_{2}$.

\subsection{Preparação de plasmídeos}

Preparações de plasmídeos foram realizadas utilizando o kit comercial Qiagen EndoFree midi ou maxi (Qiagen), seguindo as instruções do fornecedor.

\subsection{Produção de retrovírus}

Os vetores retrovirais contendo miRNA específico para p53 e o controle foram gentilmente cedidos pelo Scott Lowe, Cold Spring Harbor Laboratory, New York, EUA. Os vetores LMP e LMP-p53.1224 são derivados do MSCV e contem o gene de resistência a puromicina e o gene repórter eGFP. O vetor controle, LMP, possui a seqüência parcial de shRNA-mir, mas não oferece especificidade para nenhum mRNA alvo. O vetor LMP-p53.1224 codifica um shRNA-mir especifico para interferência com p53 murino. A expressão do shRNA-mir é dirigido pelo próprio LTR viral (DICKINS et al., 2005).

A produção de retrovírus foi realizada conforme protocolo do laboratório 
(BAJGELMAN et al., 2003; STRAUSS et al., 2005). Semear, com 24h de antecedência, $5,0 \times 10^{5}$ células da linhagem 293T para transfecção em placas $6 \mathrm{~cm}$. O DNA (10 $\mu \mathrm{g}$ de vetor viral, $7.5 \mu \mathrm{g}$ CMV-gag-pol, $5 \mu \mathrm{g}$ VSVg), misturado a $250 \mu \mathrm{L}$ de cloreto de cálcio $0,25 \mathrm{M}$, e precipitado através da adição de $250 \mu \mathrm{L}$ do tampão fosfato de sódio/HEPES HBS-2x pH 7,05 (cloreto de sódio 274mM, HEPES 40mM, fosfato monoácido de sódio $2,8 \mathrm{mM}$ ), sob agitação. A suspensão contendo o precipitado de DNA foi gotejada sobre o meio de cultura das células plaqueadas e incubado por $4 \mathrm{~h}$. As células foram submetidas a um tratamento com PBS-1X contendo $15 \%$ de glicerol (choque de glicerol) durante 3 minutos, lavadas com PBS1x e, em seguida, adicionado meio DMEM com 10\% BCS (Soro de bezerro). Vinte e quatro a quarenta e oito horas após o início da transfecção o sobrenadante viral foi coletado, centrifugado por $5 \mathrm{~min}$ a $1000 \mathrm{rpm}$ e armazenado a $-80 \stackrel{\circ}{\mathrm{C}}$.

\subsection{Transdução e seleção de B16 para produção de linhagem RNAi-p53}

Semea-se, com $24 \mathrm{~h}$ de antecedência, $5,0 \times 10^{5}$ células da linhagem B16 para transdução em placas $6 \mathrm{~cm}$. Foi utilizado $1 \mathrm{~mL}$ do vírus, que foi misturado em mais $800 \mu \mathrm{L}$ de meio RPMI com $10 \%$ de BCS adicionado a $18 \mu \mathrm{L}$ de polibreno (concentração final $8 \mu \mathrm{g} / \mathrm{mL}^{-1}$ ). A mistura foi então gotejada nas placas, seguindo de incubação por 4 horas. Após esse período de incubação foi adicionado mais $2 \mathrm{~mL}$ de RPMI às placas.

Após a transdução as células foram incubadas por 24horas e em seguida tripsinizadas e replicadas em placas de $10 \mathrm{~cm}$ e selecionadas com meio RPMI contendo puromicina (concentração final $1 \mu \mathrm{g} / \mathrm{mL}$ ). A seleção destas células foi realizada em pool, sem isolamento de clones celulares. As novas linhagens foram denominadas B16-LMP e B16-LMP-p53. Essas células foram analisadas através da técnica de Western blot para confirmar a eficácia do RNAi.

\subsection{Western blot}

Células B16-LMP e B16-LMP-p53 foram semeadas, em duplicata, em placas $10 \mathrm{~cm}$. De cada par, uma placa foi tratada com doxorrubicina, $100 \mathrm{mg} / \mathrm{mL}$, durante 24horas, e a outra placa recebeu meio sem droga. Após a retirada do meio e lavagem em PBS $1 \mathrm{X}$ as células foram lisadas com $1 \mathrm{~mL}$ de tampão de lise por 10 
minutos no gelo. As células foram raspadas, transferidas para um eppendorf e o tubo centrifugado (10min, 12000 rpm a $4{ }^{\circ} \mathrm{C}$ ). O sobrenadante foi coletado e a ele foi adicionado o anticorpo indicado $(0,5$ a $1,0 \mu \mathrm{g})$ seguido de incubação sob agitação, overnight a $4 \stackrel{\circ}{\circ} \mathrm{C}$. Na manhã seguinte $45 \mu \mathrm{L}$ de proteína A-Agarose foi adicionado ao tubo e incubado $4{ }^{\circ} \mathrm{C}$ por 1 hora sob agitação. Em seguida o tubo foi centrifugado (1min, 12000rpm a $4{ }^{\circ}$ ) e o sobrenadante removido (o sobrenadante foi armazenado no freezer $-80 \stackrel{\circ}{\circ}$ ). . O pellet foi então lavado com $1 \mathrm{~mL}$ de tampão ip por duas vezes e então foram adicionados $20 \mu \mathrm{L}$ de SDS-PAGE. As amostras foram fervidas (4min), centrifugadas à temperatura ambiente (1 min, 12000rpm) e submetidas à eletroforese em gel de acrilamida $10 \%$, a $175 \mathrm{volts}$ por aproximadamente $1 \mathrm{~h} 40 \mathrm{~min}$.

Em seguida, cortamos um pedaço de membrana (HyBond ECL) de mesmo tamanho do gel. Equilibramos gel e membranas em tampão de transferência por 10 a 15min. Montamos o sandwich de transferência. Depois, a proteína foi transferida do gel para a membrana, 1 h e $30 \mathrm{~min}$ a $25 \mathrm{volts}$. Retiramos a membrana do sandwich e deixamos overnight a $4{ }^{\circ} \mathrm{C}$ agitando com $50 \mathrm{~mL}$ de TTBS mais $5 \%$ de leite. Em seguida lava-se a membrana com TTBS uma vez por $15 \mathrm{~min}$ e outras duas vezes por 5 min. Adicionamos o anticorpo primário diluído em TTBS, deixamos agitando por 4 horas a $4 \stackrel{\circ}{\circ}$ e lavamos novamente como descrito acima. Incubamos em agitação a temperatura ambiente por 1 hora com $1 \mu \mathrm{L}$ de HRP-proteína G mais $1 \mu \mathrm{L}$ de HPRstrepavidin diluído em $10 \mathrm{~mL}$ de TTBS.

A membrana foi arrumada sobre filme plástico (PVC) e gotejado $3,5 \mathrm{~mL}$ de reagente ECL sobre a membrana, deixamos agindo por $5 \mathrm{~min}$. Removemos a membrana e embalamos em filme plástico novo para em seguida expor ao filme fotográfico.

\subsection{Construção de vetores}

A construção dos vetores foi realizada utilizando o sistema Gateway da Invitrogen. Este sistema utiliza recombinação homóloga para introduzir o cDNA de interesse no vetor escolhido. Para isto, o cDNA precisa ser montado no vetor de "entrada" que serve como doador do cDNA a ser inserido no vetor de "destino". O cDNA no vetor de "entrada" esta flanqueado por seqüências para recombinação homóloga com o vetor de "destino", que também possui seqüências específicas. O 
processo de recombinação é realizado in vitro utilizando uma enzima recombinante. Tendo o vetor de "entrada" montado, é possível repassar o cDNA para qualquer vetor (plasmidial, adenoviral, lentiviral, etc) que possui os sítios de recombinação. Descrevemos primeiramente a construção dos vetores de "entrada" (pENTR) e posteriormente descrevemos o processo de recombinação homóloga que resultou na montagem dos vetores plasmidiais e adenovirais.

\subsubsection{Construção dos vetores pENTR}

pENTReGFP: O cDNA de eGFP foi isolado do vetor pCLeGFP utilizando a enzima BamHl. O vetor pENTR2B (Invitrogen) foi preparado para receber este cDNA através de digestão com a mesma enzima BamHl e tratamento com fosfatase alkalina. Clones contendo o cDNA na orientação correta foram identificados após mapeamento com enzimas de restrição.

pENTRLuciferase: O cDNA de Luciferase foi isolado do vetor pGL3-Basic (Promega) utilizando as enzimas $\mathrm{Xbal}$, seguido de tratamento de fill-in com T4 polimerase, em seguida digerido com Kpnl. O vetor pENTR2B (Invitrogen) foi preparado para receber este cDNA através de digestão com a enzima Notl, seguido de tratamento de fill-in com T4 polimerase, em seguida digerido com Kpnl e tratamento com fosfatase alkalina. Clones contendo o cDNA na orientação correta foram identificados após mapeamento com enzimas de restrição.

pENTRp53: O vetor pENTRp53 foi construído no laboratório da Profa. Dra. Eugenia Costanzi-Strauss (ICB-USP). O cDNA de p53 selvagem humano foi inserido por clonagem tradicional.

pENTRIFN $\beta$ : $O$ cDNA de IFN $\beta$ murino foi gentilmente fornecido pelo Zhongyun Dong (University of Texas MD Anderson Câncer Center, Houston, Texas, EUA). O cDNA foi isolado após digestão com as enzimas EcoRl e Xhol e inserido no vetor pENTR2B previamente digerido com as mesmas enzimas e tratado com fosfatase alkalina. Clones contendo o cDNA na orientação correta foram 
identificados apos mapeamento com enzimas de restrição.

\subsubsection{Montagem dos vetores plasmidias via recombinação homóloga}

Os vetores de "entrada" foram recombinados com o vetor de "destino", pcDNA3.2/V5-DEST (Invitrogen) para gerar vetores plasmidiais onde a expressão do cDNA é dirigido pelo promotor CMV. Para isto, $300 \mathrm{ng}$ do vetor de "entrada" e $300 \mathrm{ng}$ do vetor pcDNA3.2/V5-DEST foram incubadas com LR Clonase (Invitrogen) a $25 \stackrel{\circ}{\circ}$ durante 24 horas. Em seguida, adiciona-se $2 \mu \mathrm{L}$ de Proteinase $\mathrm{K}$ e incuba-se por mais 10 minutos a $37^{\circ} \mathrm{C}$ e em seguida a mistura é eletroporada (200 Ohms, $25 \mu \mathrm{F}$, $2.5 \mathrm{kV}$ ) em bactérias da linhagem XL-Gold.

As bactérias foram resuspensas em $1 \mathrm{~mL}$ de meio $S O C$ e incubadas a $37{ }^{\circ} \mathrm{C}$ por 1 hora. $120 \mu \mathrm{L}$ a reação foi plaqueada em LB (LB/amp) contendo ampicilina (50 $\mu \mathrm{g} / \mathrm{mL}$ ) e incubadas a $37^{\circ} \mathrm{C}$ por no mínimo 24 horas. Após este período, foram selecionadas 24 a 30 colônias e estas expandidas individualmente em $5 \mathrm{~mL}$ de LB/amp $(50 \mu \mathrm{g} / \mathrm{mL})$ por $16-18$ horas à $37^{\circ} \mathrm{C}$, sob agitação. Os plasmídeos foram recuperados e analisados através de eletroforese em gel de agarose $1 \%$, corado com brometo de etídio e visualizado por fotografia digital.

Seguindo este esquema, identificamos os clones pcDNAeGFP, pcDNAp53 e pcDNAIFN $\beta$. A montagem do vetor pcDNALuciferase esta em andamento.

\subsubsection{Montagem dos vetores adenovirais via recombinação homóloga}

Da mesma maneira como descrito acima, os vetores de "entrada" foram recombinados com o vetor adenoviral, AdCMV/V5-DEST (Invitrogen). Seguindo este protocolo, montamos os vetores AdCMVeGFP, AdCMVLuciferase e AdCMVIFN $\beta$. O vetor AdCMVp53 foi construído com este mesmo protocolo no laboratório da Prof(a). Dra. Eugenia Costanzi-Strauss. 


\subsection{Produção inicial de preparações adenovirais}

Placas $6 \mathrm{~cm}$ foram semeadas com $7,5 \times 10^{5}$ células HEK293 e incubadas (37 ${ }^{\circ} \mathrm{C}, 5 \% \mathrm{CO}_{2}$ ) por 24 horas em meio DMEM contendo 5\% de BCS. Para a transfecção foram utilizados $5 \mu \mathrm{g}$ do vetor recombinante linearizado (através da digestão com Pacl, de modo a expor suas extremidades ITR) e adicionado a $250 \mu \mathrm{L}$ de cloreto de cálcio $(0,25 \mathrm{M})$ e precipitado através da adição de $250 \mu \mathrm{L}$ do tampão fosfato de sódio/HEPES HBS-2x pH 7,05 (cloreto de sódio 274mM, HEPES 40mM, fosfato monoácido de sódio $2,8 \mathrm{mM}$ ). A suspensão contendo o precipitado de DNA foi gotejada sobre o meio de cultura das células plaqueadas e a placa incubada por 4 horas. Em seguida, as células foram submetidas a um tratamento com PBS-1x contendo 15\% de glicerol (choque de glicerol) durante 3 minutos, lavadas com PBS1x e, em seguida, adicionou-se meio DMEM com 5\% de BCS. A coleta inicial de vírus utilizou-se o método de congelamento/descongelamento que consiste em coletar as células e o sobrenadante da placa em um tubo e passar por um ciclo, de congelamento em gelo seco seguido por banho a $37^{\circ} \mathrm{C}$, por três vezes consecutivas. Após esse processo a amostra é centrifugada (4000rpm, $5 \min$ a $4{ }^{\circ} \mathrm{C}$ ), o sobrenadante coletado aliquotado e armazenado a $-80 \stackrel{\circ}{ } \mathrm{C}$ ( $1^{\mathrm{a}}$ coleta viral).

Para amplificar os estoques virais, usou-se uma placa de $3,5 \mathrm{~cm}$ previamente plaqueada com $2,5 \times 10^{5}$ células HEK293 e acresentou-se $500 \mu \mathrm{L}$ da $1^{1}$ a coleta viral mais $500 \mu \mathrm{L}$ de meio DMEM com $2 \%$ de soro. Após 4 horas o meio DMEM $2 \%$ de soro foi trocado e a placa incubada por 4 a 10 dias até o aparecimento de efeito citopático (CPE). A coleta foi feita da mesma maneira como descrito acima (2 $2^{\underline{a}}$ coleta).

Ciclos como este foram realizados em sequência, utilizando sempre a última coleta como inóculo, afim de aumentar a concentração viral.

\subsubsection{Produção e purificação viral}

A produção e purificação final do vírus foi realizada segundo o protocolo do kit de purificação Adeno- $X^{\mathrm{tm}}$ (Clontech-EUA) que consiste em Amplificação, Extração e 
Purificação:

- Amplificação: foram transduzidas com vírus 12 placas $10 \mathrm{~cm}$ previamente plaqueada com $1 \times 10^{6}$ células HEK293. O inóculo utilizado foi a $5^{\text {a }}$ coleta de cada vírus (descrita acima). A coleta da amplificação é feita entre 2 e 3 dias quando quase todas as células estão mortas devido ao CPE.

- Extração: as células e o meio coletados na etapa de amplificação são centrifugados a 1000rpm por $5 \mathrm{mim}$, resuspendem-se as células com $5 \mathrm{~mL}$ do próprio sobrenadante e são feitos três ciclos de congelamento/descongelamento (descritos acima), afim de liberar as partículas virais das células. Realiza-se uma nova centrifugação (1000rpm, $5 \mathrm{mim}$ ) e somente o sobrenadante é coletado, misturado ao primeiro sobrenadante coletado, tratado com uma enzima para digestão de ácidos nucléicos celulares e filtrado em uma garrafa-filtro com papel filtro de 0.45 micron.

- Purificação: após a filtragem, adiciona-se um tampão de diluição ao sobrenadante que está pronto para passar pela membrana cromatográfica por meio de uma seringa. A membrana é então lavada com o tampão de lavagem e eluída em tampão de eluição. O volume final adquirido é de $3 \mathrm{~mL}$ de solução viral purificada.

Após a purificação é realizado mais um passo para trocar o tampão de eluição pelo tampão chamado "Formulation Buffer". Para tal, foi utilizado o Centricon Centrifugal Filter Device YM-50 (Millipore Corporation). Assim, por meio de repetidas centrifugações realizadas em uma Sorval Super T-21 a 4000 g, o tampão de eluição é retirado e substituído pelo "Formulation Buffer". O volume final adquirido nesta última etapa é de $2 \mathrm{~mL}$ de solução viral purificada e concentrada, e este estoque é titulado e utilizado nos experimentos realizados.

\subsubsection{Titulação do estoque viral}

Titulação biológica: O protocolo mais reprodutível e empregado para titulação biológica envolve a observação do efeito citopático (CPE) do Ad em células HEK293 após diluição seriada do vírus (NYBERG-HOFFMAN et al., 1997). Utilizando este protocolo já padronizado no SVV, nós calculamos o título viral infecioso a partir da dilução limitante (end-point) que induz morte, devido a replicação viral, nas células HEK293. 
Titulação física: Uma alíquota do estoque viral é descongelada e incubada em um tampão de lise viral (VLB) $(0,1 \%$ SDS, $10 \mathrm{mM}$ Tris-HCl [pH 7,4], 1mM EDTA) por 10 min a $56 \stackrel{\circ}{\circ}$ sob agitação.

Diferentes diluições são feitas do estoque viral em VLB: 1:2; 1:5; 1:10; 1:25; 1:50. A densidade óptica (DO) dessas diluições foi medida em espectrofotômetro a $260 \mathrm{~nm}$ e foi feito o seguinte cálculo para determinação do título:

(DO) $\times$ (diluição viral) $\times 1,1 \times 10^{12}=$ número de partículas virais $/ \mathrm{ml}$

\subsection{Ensaios de luciferase}

O impacto de p53, IFNß ou os dois na presença de promotores gênicos alvos das vias de p53 ou IFN $\beta$ foi medida através de ensaios repórter. Foram plaqueadas células B16 parentais em placas 6 -poços $\left(5,0 \times 10^{5}\right.$ céls. por poço) e transfectadas em duplicata no próximo dia pelo método de fosfato de cálcio utilizando-se as quantidades de plasmídeos conforme indicado na Tabela 1. O vetor PGT× $\beta$-Luc foi construído em nosso laboratório e possui um promotor quimérico responsivo a p53 utilizado para dirigir a expressão do gene repórter, luciferase (BAJGELMAN e STRAUSS, 2008). As construções repórter pIFNß-Luc e pIFNa-Luc foram gentilmente concedidos pelo Dr. Rongtuan Lin (McGill University, Montreal, Quebec, Canadá) e o vetor pIRF7-Luc foi doado pela Dra. Paula Pitha (Johns Hopkin University, Baltimore, MD, EUA). Estes vetores repórter contem um fragmento derivado dos promotores dos genes indicados colocados no vetor PGL-3 (Promega) e utilizado para dirigir expressão do gene repórter luciferase (LU et al., 2000; SERVANT et al., 2003). Também foi usado esperma de salmão para completar a quantidade de DNA usado na transfecção que no caso foi de $10 \mu \mathrm{g}$ totais por poço. 
Tabela 1. Quantidades de DNA

\begin{tabular}{c|c|c|c|c}
\hline $\mathrm{N}^{\circ}$ poço & $\begin{array}{c}\text { esperma de } \\
\text { salmão }\end{array}$ & repórter & pcDNA-IFN $\beta$ & pcDNA-p53 \\
\hline $1-2$ & $10 \mu \mathrm{g}$ & -- & -- & -- \\
\hline $3-4$ & $8 \mu \mathrm{g}$ & $2 \mu \mathrm{g}$ & -- & -- \\
\hline $5-6$ & $4 \mu \mathrm{g}$ & $2 \mu \mathrm{g}$ & $4 \mu \mathrm{g}$ & -- \\
\hline $7-8$ & $4 \mu \mathrm{g}$ & $2 \mu \mathrm{g}$ & -- & $4 \mu \mathrm{g}$ \\
\hline $9-10$ & -- & $2 \mu \mathrm{g}$ & $4 \mu \mathrm{g}$ & $4 \mu \mathrm{g}$ \\
\hline $11-12$ & $8 \mu \mathrm{g}$ & -- & -- & -- \\
\hline
\end{tabular}

Depois de 24h da transfecção as células foram tripsinizadas, lavadas em PBS $1 \mathrm{X}$ e ressuspendidas em $100 \mu \mathrm{L}$ de $0,1 \mathrm{M} \mathrm{KPO}_{4} \mathrm{pH} 7,8 / 1 \mathrm{mM}$ EDTA para então serem lisadas em três passagens consecutivas de gelo seco/banho $37^{\circ} \mathrm{C}$. Após esse processo de lise as células foram centrifugadas ( $5 \mathrm{~min}, 4000 \mathrm{rpm}$ a $4 \stackrel{\circ}{\circ} \mathrm{C}$ ) e o sobrenadante coletado e transferido para um tubo novo. As analises de luciferase e de proteína foram feitas a partir desse sobrenadante.

Para o ensaio de luciferase utilizou-se $50 \mu \mathrm{L}$ de solução de luciferina (substrato de luciferase, Promega) mais $10 \mu \mathrm{L}$ da amostra, que foi vortexada e analisada utilizando-se o equipamento para leitura Monolight 2010, avaliando-se a intensidade de emissão de luz (RLU).

A concentração de proteína foi analisada no espectrofotômetro em um comprimento de onda $595 \mathrm{~nm}$. Para este experimento adicionou-se a um eppendorf, $800 \mu \mathrm{L}$ de água, $200 \mu \mathrm{L}$ de reagente Bradford Protein Assay (Bio-Rad) mais $2 \mu \mathrm{L}$ da amostra. Para a curva padrão, usamos $800 \mu \mathrm{L}$ de água, $200 \mu \mathrm{L}$ de corante e quatro amostras diferentes de albumina (BSA) com concentrações conhecidas.

Os valores obtidos no espectrofotômetro foram passados para analise em Microsoft Office Excel e utilizados para determinar a atividade de luciferase/ $\mu \mathrm{g}$ de proteína. Em seguida, os valores foram normalizados considerando-se a atividade observada no controle do vetor repórter junto com seu indutor. 


\subsection{Citometria de fluxo}

As células transfectadas ou transduzidas com construções contendo o gene marcador eGFP são analisadas pelo método de citometria de fluxo (FACS SCALIBUR, Becton Dickinson, EUA), avaliando-se a porcentagem de células transduzidas ou transfectadas, e o nível de expressão do gene. Para analise dos dados utiliza-se o software Cell Quest (Becton Dickinson, EUA), considerando-se a intensidade média das células transduzidas.

O procedimento para analisar as células por citometria consiste em tripsinizar as células aderidas, centrifugar (1000rpm, $5 \mathrm{~min}$ a $4 \stackrel{\circ}{\circ}$ ), lavar uma vez com PBS-1x e centrifugar novamente. O sobrenadante é descartado e as células ressuspensas em PBS-1x, para assim, executar a aquisição da amostra no citômetro.

\subsection{ELISA}

O teste de ELISA (Enzyme Linked ImmunoSorbent Assay) se baseia em reações antígeno-anticorpo detectáveis através de reações enzimáticas. Os ensaios foram feitos segundo o protocolo dos fabricantes (PBL Biomedical, para detecção de IFNß e Roche, para detecção do p53). A absorbância (comprimento de onda a 450 $\mathrm{nm}$ ) foi determinada pelo leitor de microplacas Victor ${ }^{\mathrm{Tm}}$ (Perkin-Elmer, EUA). 


\section{RESULTADOS}

\subsection{Knock-down de p53 na linhagem B16 via miRNA}

Para o knock-down de B16 nosso grupo resolveu utilizar a tecnologia do shRNA-mir, que, como visto em outros trabalhos, é mais eficiente e mais simples de se trabalhar (DICKINS et al., 2005). Nós começamos produzindo os retrovírus LMP (como controle) e LMP-p53 que contem o shRNA-mir específico para p53 murino. Os vírus foram transduzidos nas células B16. Após a transdução, as células foram selecionadas em massa, com puromicina, e expandidas. As células foram plaqueadas em duplicata, onde uma replicata de cada par foi tratada com doxorrubicina. Quando analisadas por Western blot (Figura 3), nós observamos a ausência de p53 na linhagem B16-LMP-p53 sem tratamento de doxorrubicina. O tratamento com droga foi menos eficaz em ativar p53 na linhagem B16-LMP-p53 quando comparado com o controle, B16-LMP. Nós confirmamos este resultado com analise do alvo transcricional de p53, p21. Tratamento de células B16-LMP-p53 com doxorrubicina não resultou no aumento do p21, como observado na linhagem B16LMP. Os dados obtidos até agora, infelizmente, não estão muito limpos, porém, a repetição do ensaio de Western está em andamento e esperamos melhorar este resultado e incluir o controle interno, $\beta$-actina. No entanto, o resultado nos fornece uma boa base para acreditar que o LMP-p53 esta funcionando corretamente. 


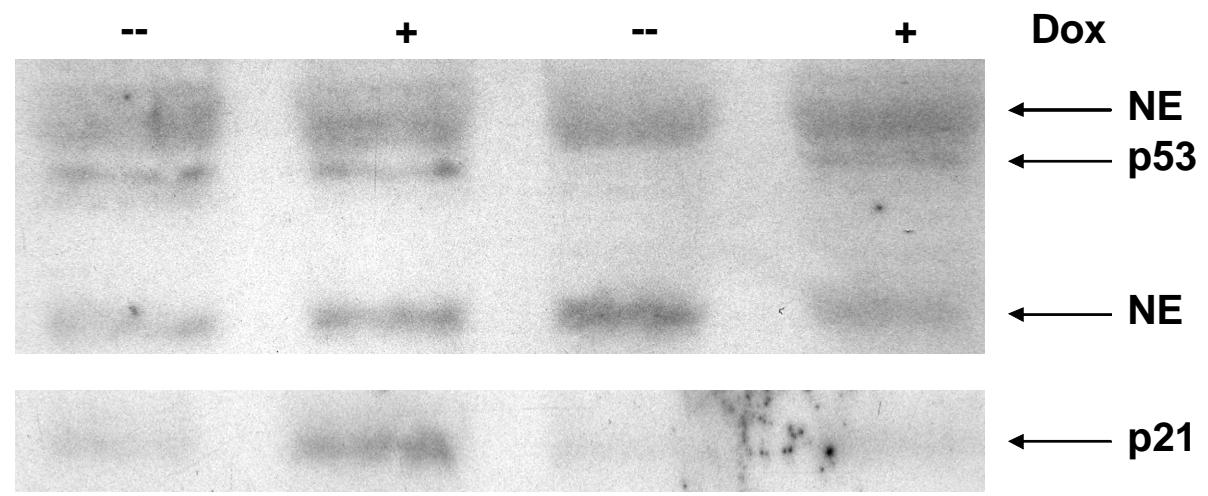

Figura 3: Analise por Western blot demonstra a queda de p53 na célula B16-LMP-p53. Para este ensaio, células B16-LMP (LMP) ou B16-LMP-p53 (LMP-p53) foram tratadas ou não com $100 \mathrm{ng} / \mathrm{ml}$ de doxorrubicina (Dox) durante 24 horas. O lisado protéico foi utilizado no ensaio de Western blot (conforme descrito em Materiais e Métodos) utilizando anticorpos específicos para p53 (Pab 421, Oncogene Research) ou p21 (Santa Cruz Biotechnologies). Banda não-específica (NE) incluído para demonstrar que alterações no nível de p53 não foram devidas a inconsistência em manipulação das amostras.

Com o intuito de demonstrar uma redução na atividade de p53, as linhagens foram transfectadas com uma construção repórter, pPGTxß-Luc, que utiliza um promotor responsivo a p53 para dirigir expressão de luciferase (BAJGELMAN e STRAUSS, 2008) e, posteriormente, tratadas com doxorrubicina, um quimioterápico que ativa p53. Como visto na Figura 4, o nível de atividade do repórter foi reduzido na linhagem B16-LMP-p53 em comparação com B16-LMP. Também, a indução de p53 com doxorrubicina foi menos marcante nas células B16-LMP-p53 em comparação com B16-LMP. Com este ensaio funcional, acreditamos que a atividade de p53 foi reduzida nas células B16-LMP-p53. 


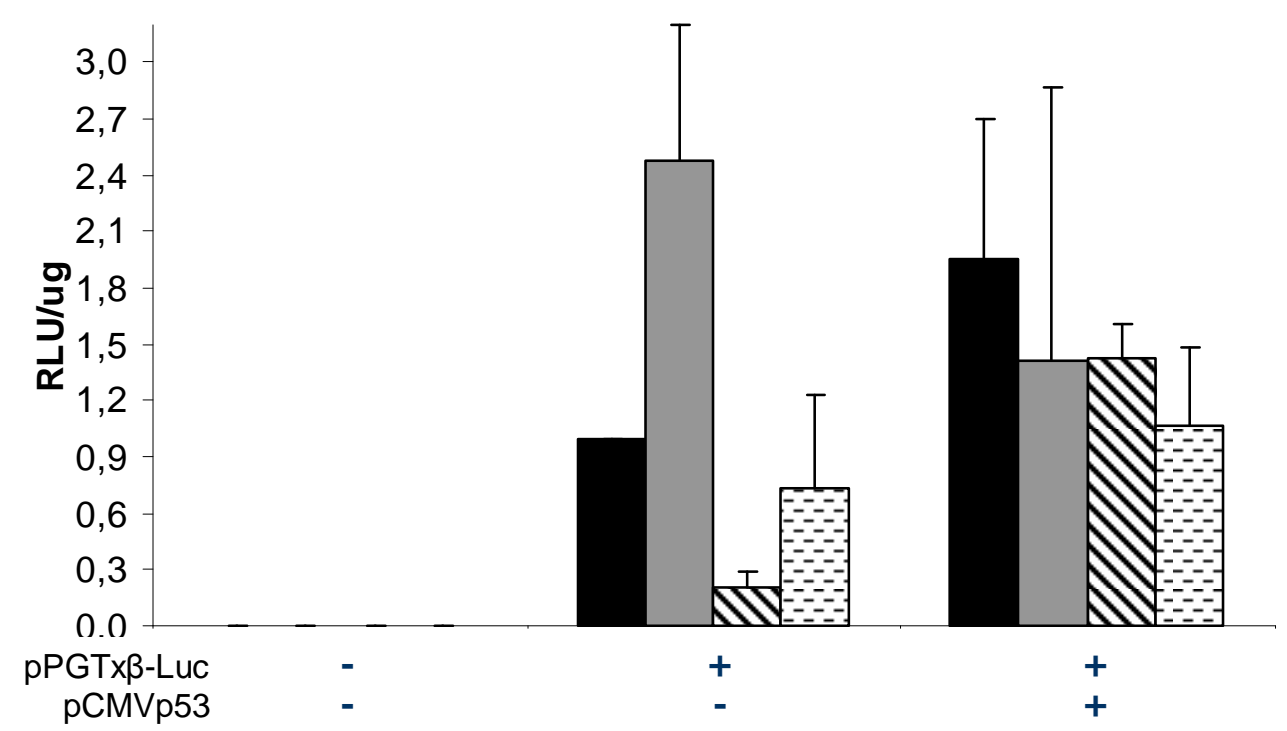

Figura 4: Ensaio de luciferase. Células das linhagens B16LMP (LMP) ou B16-LMP-p53 (LMP-p53) que foram tratadas ou não com $100 \mathrm{ng} / \mathrm{ml}$ de doxorrubicina (dox) por 24 horas após a transfecção.

\subsection{Construção e caracterização de vetores plasmidiais (pcDNA3) portadores dos cDNAs para eGFP, Luciferase, p53 e IFN $\beta$}

A tecnologia de clonagem Gateway (Invitrogen) (Figura 5) é uma plataforma universal que permite inserir o seu gene de interesse em vários sistemas de expressão. Segundo o fornecedor, a orientação e a fase de leitura são mantidas com alta eficiência, efetivamente eliminando a necessidade de um seqüenciamento secundário ou uma subclonagem depois que o vetor de "entrada" está pronto. 


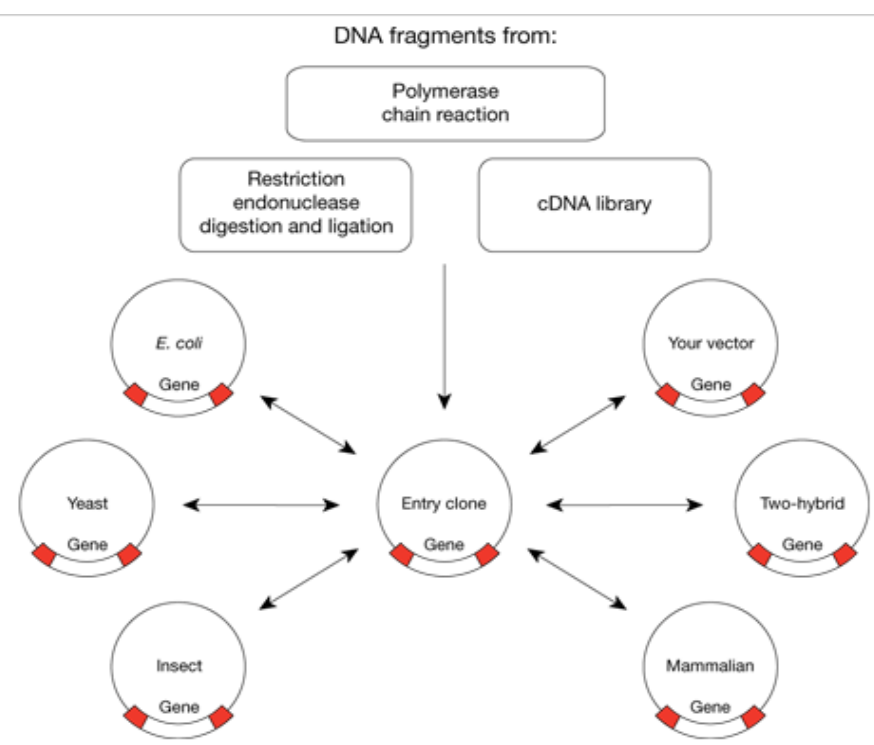

Figura 5: Tecnologia Gateway ${ }^{\circledR}$ facilita a clonagem dos genes em múltiplos vetores via recombinação sítio-específico. Uma vez que o gene esta clonado no vetor ENTR pode-se mover o fragmento de DNA para um ou mais vetores destinos simultaneamente.

pENTR: O vetor de "entrada" pENTR é o primeiro passo para construção dos vetores, tanto de cDNA como os de Adenovírus. Os genes de interesse, Luciferase, eGFP, p53 e IFN $\beta$ foram inseridos no vetor pENTR (Figura 6) por clonagem tradicional, utilizando-se as enzimas do sitio de clonagem, em seguida foi verificado se $o$ inserto estava presente assim como, se sua orientação estava correta.
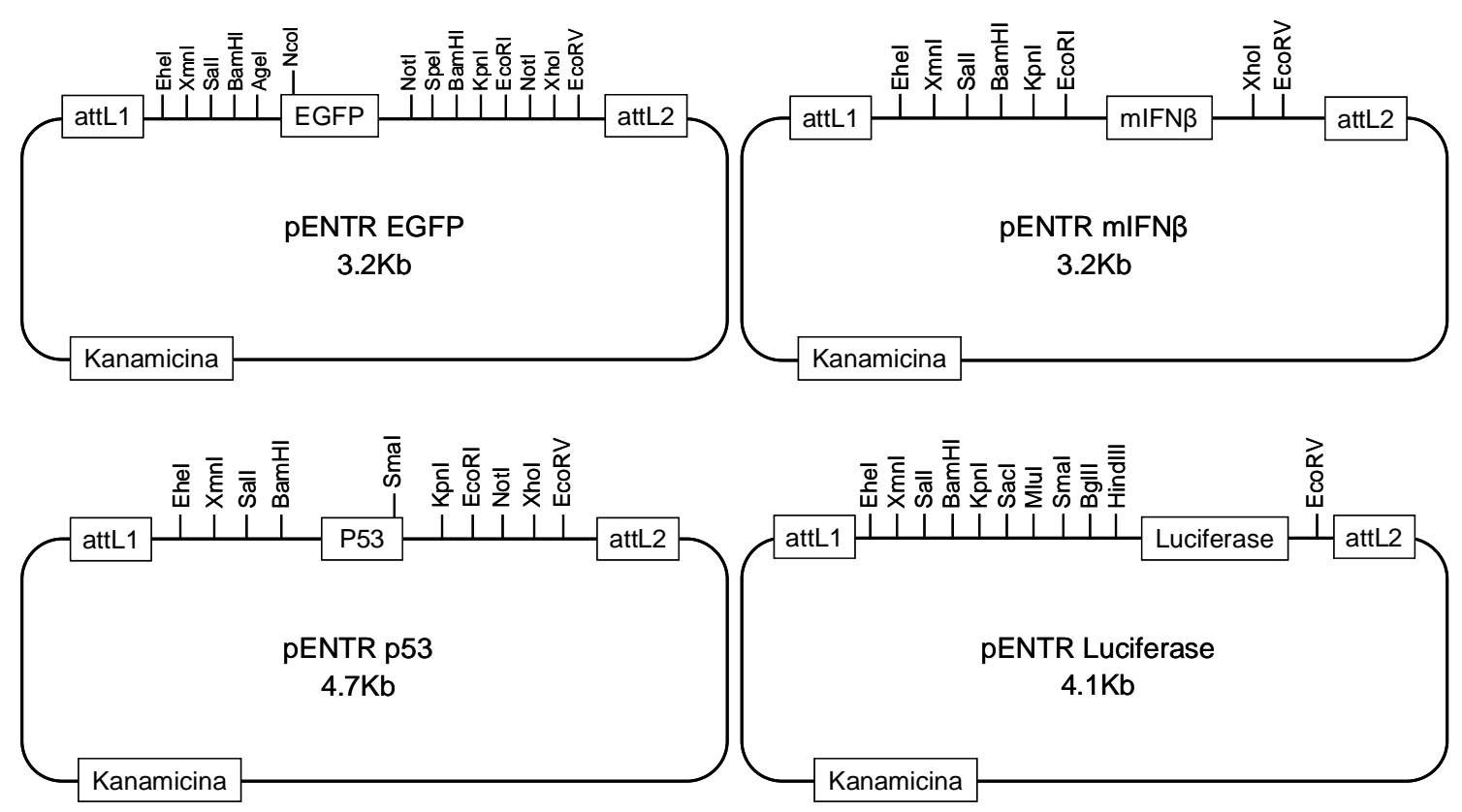

Figura 6: Mapas dos vetores de pENTR. 
pcDNA-DEST: Todos os vetores Gateway de destino possuem os sítios attR e attL para recombinação com os vetores pENTR. Por meio de recombinação homologa, geramos um conjunto de vetores contendo os cDNAs de interesse, mas todos derivados do mesmo vetor de expressão. Como mostrado na Figura 7, foi inserido, por recombinação homóloga, os cDNAs de eGFP, p53 ou o mIFN $\beta$ no vetor $p^{p C D N A}{ }^{\text {TMM }} /$ V5-DEST da Invitrogen. A recombinação entre os vetores $p E N T R L u c i f e r a s e$ e pcDNA está em andamento. Como descrito a seguir, ensaios funcionais utilizando estes vetores plasmidiais já foram abordados. Pretendemos verificar a expressão dos transgenes p53 e mIFN $\beta$ utilizando kits de ELISA comerciais.

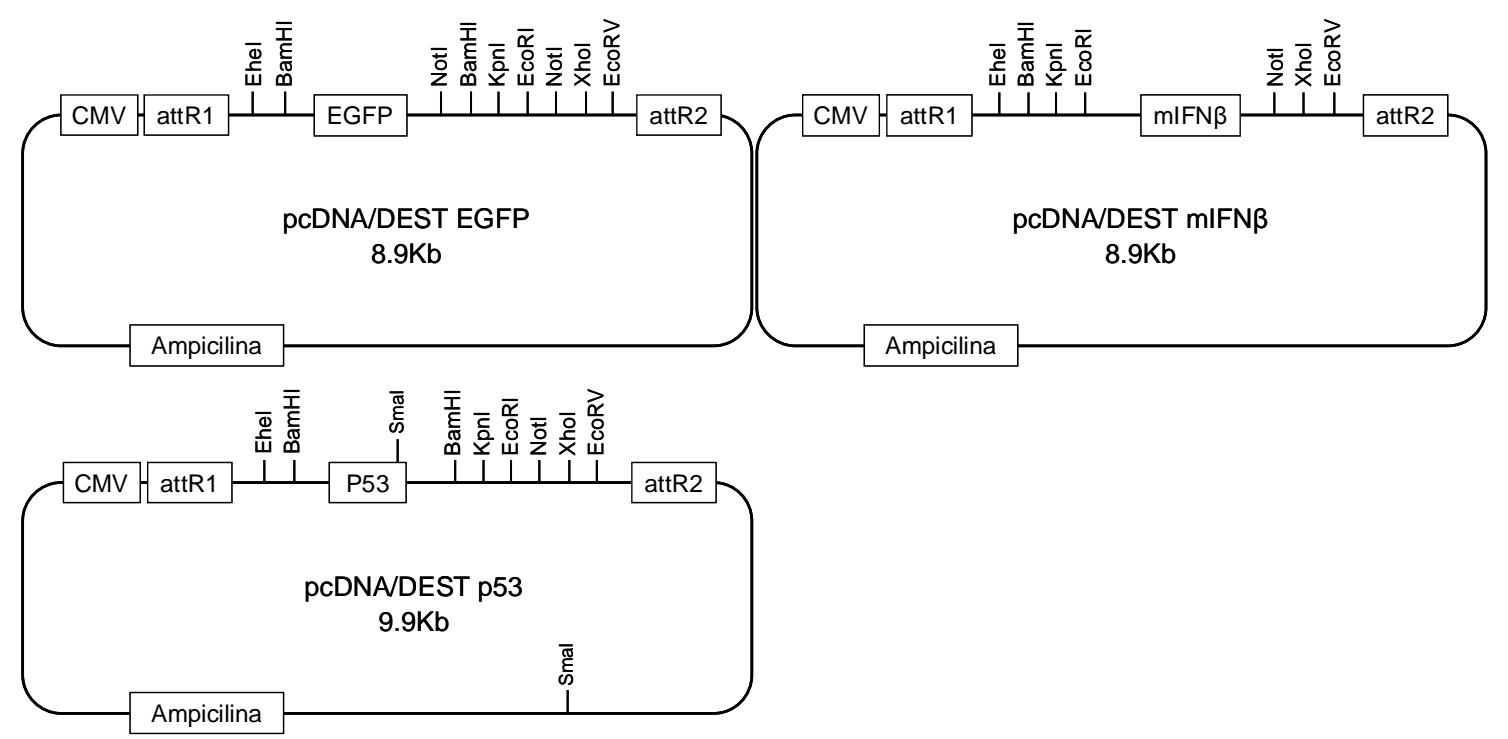

Figura 7: Mapas dos vetores de pcDNA.

Após a construção dos vetores da plataforma pcDNA3, o próximo passo é a caracterização ou validação das construções para confirmação dos trangenes inseridos no vetor. Para o pcDNAeGFP foi realizado um ensaio de citônetro de fluxo para verificar a expressão do eGFP (Figura 8). Para o vetor pcDNAIFN $\beta$ foi realizado um ensaio de ELISA para verificar a expressão de IFNß (Figura 9). No caso do pcDNAp53, ensaios estão em andamento atualmente. 


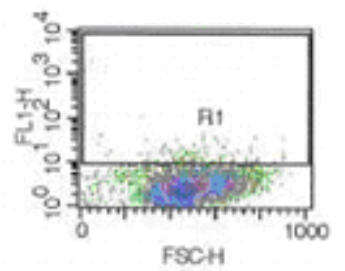

$\frac{\text { Region } \$ \text { Total } Y \text { Mown }}{\text { A1 } 17425.61}$

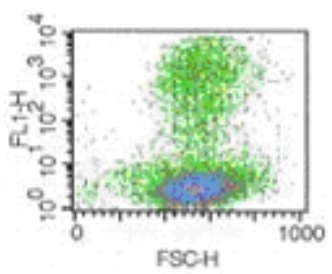

$\mathrm{FSCH}$

Figura 8: Analise de expressão de GFP do vetor pcDNAeGFP na linhagem HEK293.

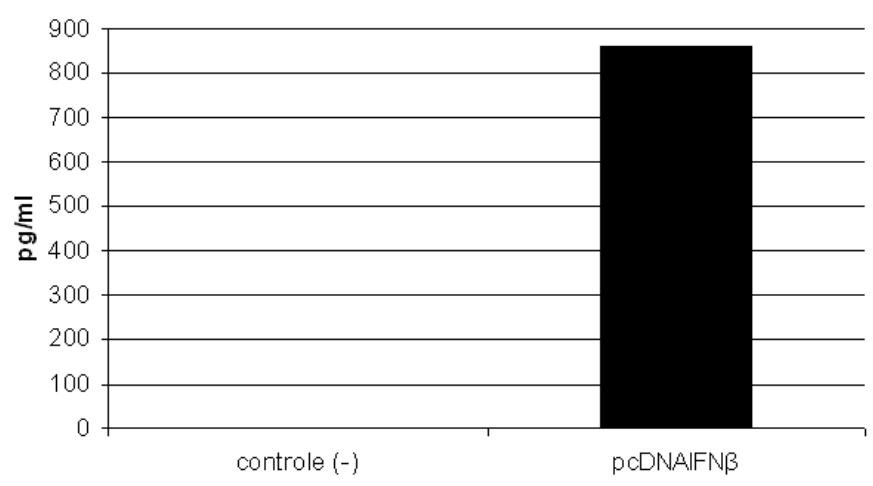

Figura 9: Ensaio de ELISA mostrando expressão de IFN $\beta$ do vetor pcDNAIFN $\beta$ na linhagem B16.

\subsection{Construção e caracterização de vetores adenovirais (AdCMV) portadores dos cDNAs para eGFP, Luciferase, p53 e IFN $\beta$}

Assim como os vetores de destino pcDNA, os vetores pAdCMV também possuem os sítios attR e attL para recombinação com os vetores pENTR. Foi realizada a recombinação para gerar os vetores adenovirais com expressão do transgene dirigida pelo promotor CMV. Para isto, os vetores pENTR, descritos acima, foram recombinados com o vetor pAdCMV/V5-Dest, gerando pAdCMV-p53, pAdCMV-IFN $\beta$, pAdCMV-eGFP e pAdCMV-luciferase (Figura 10). 

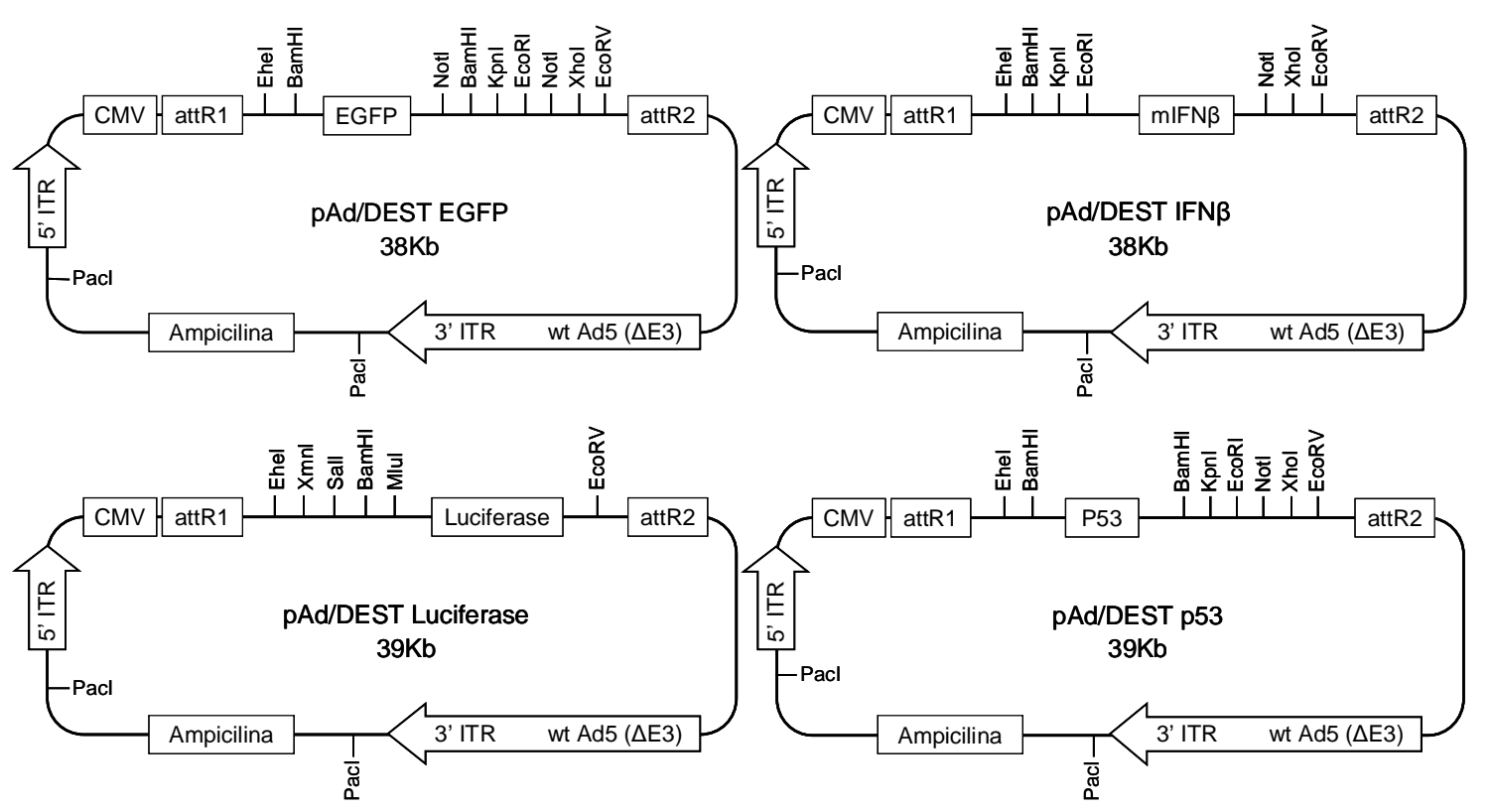

Figura 10: Mapas dos vetores de pAdCMV

Temos interesse na utilização de vetores virais em ensaios de co-transdução após a produção e titulação dos vírus. Com os primeiros lotes de vírus, verificamos a expressão do transgene de GFP com ensaio de citômetro de fluxo (Figura 11), pretendemos verificar a expressão dos transgenes p53 e mIFN $\beta$ utilizando kits de ELISA comerciais.
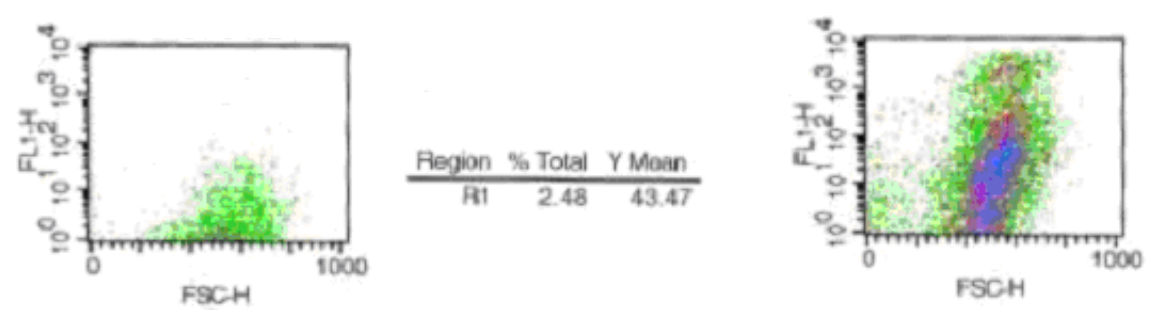

$\frac{\text { Pogion } \approx \text { Total } Y \text { Moan }}{\text { R1 } 59.51 \quad 365.62}$

Figura 11: Analise de expressão de GFP do vetor AdCMVeGFP. 


\subsection{Ensaios para explorar possíveis interações entre as vias de p53 e IFN $\beta$, incluindo ensaios repórter e de ciclo celular}

Utilizando os novos vetores plasmidiais descritos acima, nós abordamos nosso primeiro ensaio funcional em busca do impacto da presença de p53 e/ou IFN $\beta$ na ativação de promotores alvos destas vias. Células B16 parentais foram cotransfectadas com uma construção repórter contendo um promotor responsivo a p53 ou um promotor gênico que participa na via de IFN junto com os vetores de expressão de p53, IFNß ou os dois.

$\mathrm{Na}$ célula B16, a construção repórter responsivo a p53, PGTxß-Luc, foi ativada na presença de p53 exógeno (Figura 12). Na presença de IFN $\beta$, a atividade de luciferase foi ligeiramente ativada. Enquanto que na presença de ambos p53 e IFN $\beta$, o repórter demonstrou um nível intermediário.

A construção repórter IFN $\beta$-Luc foi induzida na presença do vetor pcDNAIFN $\beta$, mas a presença de p53 não teve um impacto significante (Figura 12). Em comparação, a construção repórter IFNa-Luc foi fracamente ativada por p53 ou IFNß, no entanto a combinação destes não levou uma indução maior (Figura 12). Porem, a presença de IFN $\beta$, mas não p53, foi um indutor forte da atividade do promotor de IRF7 (Figura 12). 

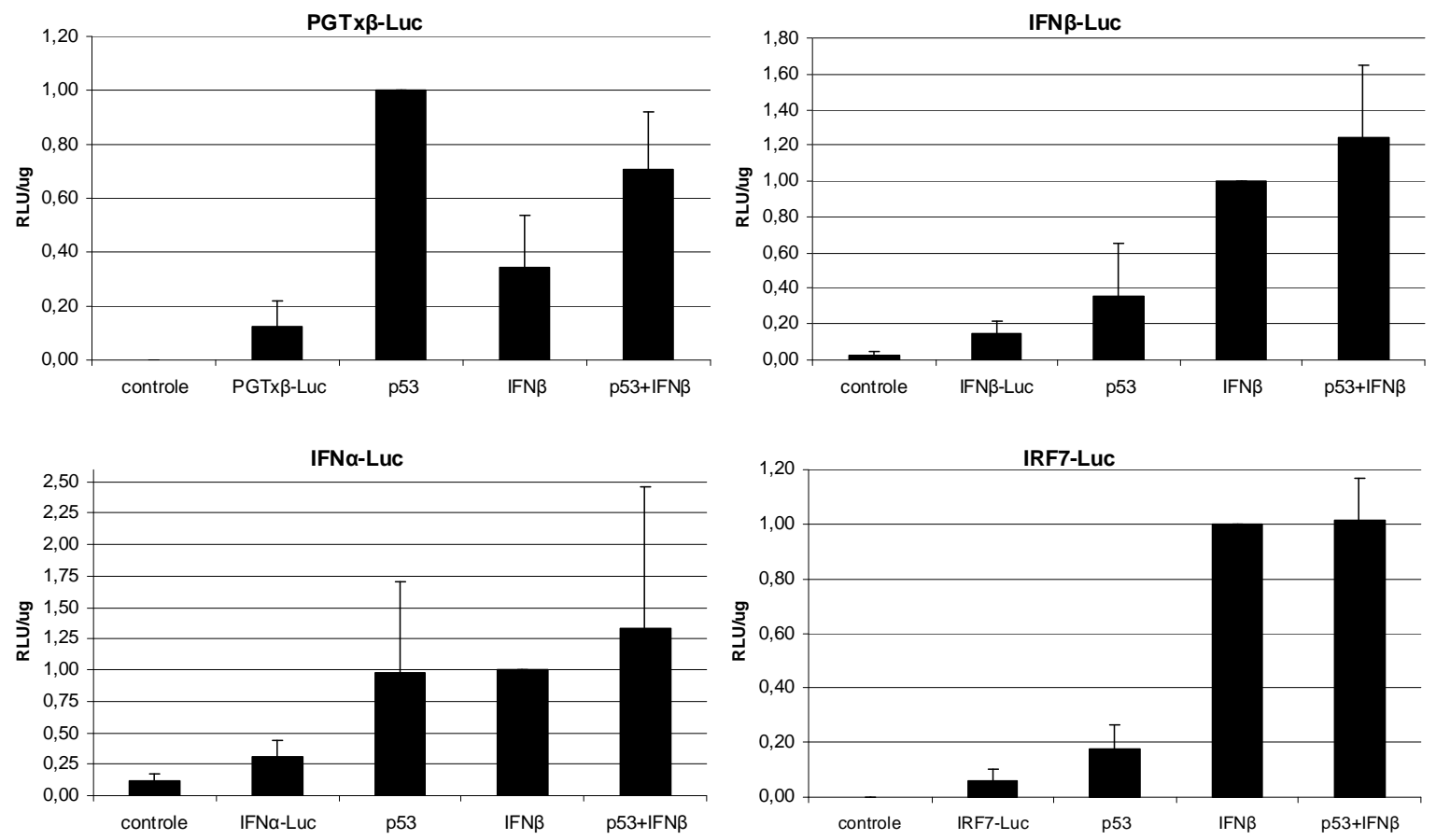

Figura 12: Analise de luciferase: PGTx $\beta$-Luc: normalizado pelo repórter PGTx $\beta$-Luc mais o indutor p53; IFNß-Luc: normalizado pelo repórter IFN $\beta$-Luc mais o indutor IFN $\beta$; IFNa-Luc: normalizado pelo repórter IFNa-Luc mais o indutor IFNß; IRF7-Luc: normalizado pelo repórter IRF7-Luc mais o indutor IFNß. 


\section{DISCUSSÃO}

A meta deste trabalho foi a construção de uma série de ferramentas para serem utilizadas na exploração de interações entre p53 e IFN $\beta$ num modelo de melanoma. Nossa primeira ferramenta foi a construção de uma linhagem celular, derivada de B16, com a expressão de p53 reduzida por meio de miRNA. Futuramente, pretendemos utilizar esta ferramenta para avaliação da resposta da célula à IFN $\beta$ sem a presença do p53 endógeno.

Outra ferramenta desenvolvida neste projeto foi a construção de vetores plasmidiais e adenovirais portadores de eGFP, Luciferase, p53 ou IFN $\beta$ murino, que são utilizados para introduzir estes fatores sozinhos ou em combinação, em células alvo para avaliação do seu impacto em expressão gênica, proliferação ou morte celular. Simplesmente pelo motivo de que a construção dos vetores plasmidiais serem mais rápido nós os utilizamos para ensaios preliminares. Onde os plasmídeos contendo o cDNA de luciferase dirigido por um promotor responsivo a p53 ou responsivo a fatores do sistema interferon foram co-transfectados em células da linhagem B16 com os plasmídeos contento os vetores de expressão para p53 e IFN $\beta$. Mesmo confirmando a atividade de p53 ou IFN $\beta$ sozinhos, validando desta forma a construção dos vetores, não foi observado um efeito aditivo desses fatores em conjunto utilizando este tipo de ensaio.

Acreditávamos que a parte de padronização e construção das ferramentas seria rápida, pois nosso laboratório já possuía praticamente todos os vetores que seriam utilizados neste projeto. Outros membros do nosso laboratório já haviam construído os vetores de p53 e IFN $\beta$, assim como os repórteres (eGFP e luciferase). Neste caso, os cDNAs foram inseridos no sistema adenoviral comercial, Adenovator (Qbiogene). A montagem do adenovirus neste sistema consiste em dois passos, a montagem de um vetor intermediário e, posteriormente, a recombinação homóloga entre este e o vetor adenoviral em si. Os vetores intermediários devem servir como vetores de expressão dado que contem um promotor, o cDNA de interesse e um sinal de poli-adenilação. Conforme o plano original deste projeto, estes vetores do sistema Adenovator foram testados em ensaios preliminares, porém encontramos dificuldades com estes vetores. Os vetores intermediários, quando utilizados em ensaios repórter, renderam resultados confusos e pouco reprodutíveis. Outros membros do laboratório testaram os adenovirus do sistema Adenovator e também 
encontraram dificuldades, como baixa expressão do transgene. Sem confiança nos vetores do sistema Adenovator, estes primeiros ensaios foram abandonados e procuramos novas alternativas.

A segunda tentativa de explorar as interações entre p53 e IFN $\beta$ também foi através do ensaio repórter, mas utilizando vetores plasmidiais de expressão já prontos no laboratório. No entanto, os vetores plasmidiais eram de plataformas diferentes, os cDNAs de p53 e de luciferase estavam no vetor Rc/CMV e o cDNA de IFN $\beta$ estava no pcDNA3. Infelizmente, estes ensaios também nos trouxeram mais dúvidas do que respostas, pois os resultados foram muito pouco reprodutíveis. Foi formulada uma hipótese de que estes ensaios não deram certos devido à mistura das plataformas prejudicando a interpretação do ensaio.

Para contornar estes problemas, todos os cDNAs foram inseridos no sistema Gateway (Invitrogen) com o intuito de construir uma série de vetores confiáveis e utilizar uma única plataforma. A partir daí, foi construído os vetores plasmidiais no pcDNA3 e os adenovirais no AdCMV. Com esse intuito, de contornar os problemas anteriores com os vetores diferentes, focamos em construir vetores confiáveis, montados em uma única plataforma, para realizar os experimentos com menos variáveis.

A construção dos vetores utilizando o sistema Gateway foi realizada com sucesso, com a exceção do vetor pcDNAluciferase que por algum motivo não conseguimos cloná-lo. No entanto os demais vetores foram todos construídos assim como os vírus derivados do vetor AdCMV.

O grande benefício de se utilizar a tecnologia de clonagem Gateway se deve ao fato de ser uma plataforma universal que permite inserir o seu gene de interesse em vários sistemas de expressão uma vez que o vetor de "entrada" está pronto, facilitando a clonagem dos genes nos vetores destinos via recombinação sítioespecífico. Agilizando assim as clonagens, pois pode inserir 0 gene simultaneamente em mais de um vetor destino, neste caso no pcDNA e no AdCMV. Alem do mais, futuramente este mesmo sistema pode ser utilizado para inserir nossos genes de interesse em conjunto com outros promotores, outros arranjos como a montagem de um vetor bisistrônico e também outros vírus.

De posse de todas as construções do vetor pcDNA, dado que os vírus das construções AdCMV ainda não estavam prontos, foram realizados ensaios funcionais para avaliar a interação de p53 e/ou IFN $\beta$ na ativação de promotores 
alvos destas vias. Células B16 parentais foram co-transfectadas com uma construção repórter contendo promotor responsivo a p53 ou um promotor gênico que participa na via de IFN junto com os vetores de expressão de p53, IFN $\beta$ ou os dois. A construção repórter responsivo a p53 a atividade de luciferase foi ativada na presença de p53 exógeno. Na presença de IFN $\beta$, a atividade de luciferase foi ligeiramente ativada. Enquanto que na combinação de p53 e IFN $\beta$, o repórter demonstrou um nível intermediário.

A construção repórter IFN $\beta$-Luciferase foi induzida na presença do vetor de IFN $\beta$, mas a presença de p53 não teve impacto significante, mesmo quando IFN $\beta$ foi incluido. Em comparação, a construção repórter IFNa-Luciferase foi fracamente ativada por p53 ou IFN $\beta$, no entanto a combinação destes não levou uma indução maior. Porém, a presença de IFN $\beta$, mas não p53, foi um indutor forte da atividade de luciferase no promotor IRF7. A construção repórter responsivo a p53, PGTxß-Luc, foi ativada na presença de p53 exógeno. Na presença de IFN $\beta$, a atividade de luciferase foi ligeiramente ativada, enquanto que na presença de ambos p53 e IFN $\beta$, o repórter demonstrou um nível intermediário, porém não muito significativo para nossos dados.

Primeiramente estes dados indicam que os vetores, por apresentarem indução da atividade de luciferase em seus promotores responsivos, são confiáveis, pois expressam o gene de interesse normalmente, no entanto um ensaio de ELISA para os vetores de p53 e IFN $\beta$ é necessário para confirmar diretamente a expressão a partir destes vetores. Em segundo, é necessário melhorar o modelo de ensaio para explorar melhor esta relação de p53/IFN $\beta$, neste caso utilizando o adenovirus, pois reduziria os problemas da transfecção como baixo índice de células transfectadas e manipulação. Também, para melhorar o ensaio seria interessante realizar um estudo cinético desse experimento, já que esses dados são analisados apenas 24horas após a transfecção. Analisar esse experimento com diferentes intervalos de tempo após transfecção serviria para fornecer dados da ativação de p53 e/ou IFN $\beta$ em função do tempo.

Alem disso, após várias tentativas e repetições destes ensaios nós achamos que o fato de p53 endógeno estar em estado selvagem e apenas desativado (GIGLIA-MARI e SARASIN, 2003; SANDOVAL et al., 2004), a idéia de adicionar mais p53 não surtirá efeito, então pensamos que utilizar o p19arf no lugar de p53, pode ser mais interessante e mais importante para controle do melanoma (HA et al., 
2008; BOX e TERZIAN, 2008).

No entanto um ponto positivo nessa estratégia é a utilização de vetores de transferência gênica para expressão do gene de interesse, pois na grande maioria dos trabalhos publicados é mais comum o uso de proteína recombinante para adicionar IFN às células, mas esta utilização é limitada pela curta meia vida da proteína e toxicidade associada a altas doses (SABEL e SONDAK, 2003; KAVANAGH et al., 2005). A utilização do vetor plasmidial ou viral no lugar da proteína recombinante apresenta uma série de vantagens, como o efeito localizado do tratamento e a contínua expressão do gene pelo promotor evitando novas doses como no uso de proteína. Como nosso alvo é o tratamento do melanoma, uma alternativa ao uso da proteína recombinante seria a terapia gênica com IFN $\beta$. Pelo menos 6 protocolos clínicos de terapia gênica foram abordados utilizando IFN $\beta$ como gene terapêutico e foi observado uma indução de apoptose, do processo inflamatório e ativação do sistema imune, alem de mostrarem que células resistentes ao tratamento com proteína recombinante foram sensíveis a tratamento gênico com IFN $\beta$. Outros protocolos relacionados ao teste de segurança e aplicabilidade da terapia gênica com IFN $\beta$ sugerem que o uso de terapia gênica de IFN $\beta$ pode ser seguro o eficaz (STERMAN et al., 2007; WAKABAYASHI et al., 2008; CHIOCCA et al., 2008).

Assim como os vetores plasmidiais, também foi realizada a recombinação para gerar os vetores adenovirais, Para isto, os vetores $p E N T R$, foram recombinados com o vetor pAdCMV/V5-DEST gerando os vetores AdCMV contendo os cDNAs de p53, IFN $\beta$, eGFP e luciferase. Temos interesse na utilização de vetores virais em ensaios de co-transdução após a produção e titulação viral. A produção e titulação ocorreu sem problemas, gerando um volume de $3 \mathrm{~mL}$ para cada vírus, com um título de $2 \times 10^{9} \mathrm{pfu} / \mathrm{mL}$ para p AdCMVp53, $2 \times 10^{9} \mathrm{pfu} / \mathrm{mL}$ para o AdCMVIFN $\beta$ e $2 \times 10^{10} \mathrm{pfu} / \mathrm{mL}$ para o AdCMVeGFP. O AdCMVluciferase foi produzido porém não foi titulado pois optamos por utilizar somente o AdCMVeGFP como controle. Para a caracterização viral foi realizado um ensaio de citômetro de fluxo para o AdCMVeGFP, que mostrou expressão de GFP validando o vetor. Para os adenovirus contendo p53 e IFN $\beta$ serão realizados ensaios de ELISA.

Como dito acima, os adenovirus serão utilizados para ensaios de cotransdução para verificar a interação de p53/IFN $\beta$ e possivelmente também com p19arf. Estes experimentos poderão ser realizados diretamente após a transdução 
por evitar as limitações da transfecção, pois não necessitam de toda a manipulação celular que ocorre com os plasmídeos e muito menos a utilização de cloreto de cálcio e HBS, sendo que para a transdução, resumidamente, só é preciso calcular o MOI (número de partículas virais por célula) e juntar as células. No caso dos adenovirus eles serão adicionados as células e posteriormente poderão ser feitos ensaios de RT-PCR, ciclo celular ou até mesmo para ensaios in vivo usando diretamente o vírus ou as células após transdução.

Nossa escolha em usar o adenovirus para os ensaios e para uma futura terapia gênica tem se fortalecido não somente pelas vantagens intrínsecas ao vírus, mas também porque há pelo menos mais três publicações com protocolos clínicos que utilizam o adenovirus como vetor de terapia gênica. Segundo os dados da literatura o uso de adenovirus é seguro e eficaz (STERMAN et al., 2007; WAKABAYASHI et al., 2008; CHIOCCA et al., 2008).

Futuramente serão feitos ensaios básicos para avaliar a interação dos vetores de p53/IFN $\beta$ e seus sistemas, já que na literatura existem muito poucos trabalhos que utilizem o IFN $\beta$ como vetor, a maioria usa a proteína recombinante para adicionar o IFN às células. E como discutido acima, o uso da proteína recombinante apresenta algumas limitações como a necessidade de se fazer várias aplicações com altas doses (TAKAOKA et al., 2003; YOSHIDA et al., 2004). O uso de vetores é uma estratégia com intuito de contornar essas limitações da proteína recombinante, há pelo menos 6 protocolos clínicos que utilizam o IFN $\beta$ como vetor de terapia gênica de câncer, no entanto nenhum para tratamento de melanoma (http://www.wiley.co.uk/genmed/clinical/).

Dados da literatura indicam que a indução de p53 por IFN $\beta$ é causada por ativação transcricional, sobretudo, foi demonstrado que apoptose de células tumorais com tratamento com proteína recombinante de IFN foi aumentado na presença de p53, assim o efeito pró-apoptótico de IFN envolve p53 (SANDOVAL et al., 2004). No caso de melanoma, segunda a literatura, o p19arf seria mais importante já que este impede a interação de mdm2 com p53, permitindo que p53 promova a parada da progressão celular e induza apoptose ou senescência (HA et al., 2008).

Numa fase precoce o IRF-3 se torna ativo induzindo expressão de IFN $\beta$, o IFN $\beta$ presente se liga ao seu receptor e torna ativo o complexo ISGF3 que por sua vez ativa o promotor transcricional IRF-7. Numa fase mais tardia de ativação a 
indução de IRF-7 coopera com IRF-3 ativando transcricionalmente IFNa/ $\beta$ que em conjunto se ligam ao seu receptor fortalecendo o sistema IFN por um mecanismo de feedback positivo. A ativação do sistema IFN resulta na expressão de uma gama de fatores que somados podem ativar o sistema imune via células $T$, maturação de células dendríticas, atração de macrófagos e apoptose (SATO et al., 2001; CHAWLA-SARKAR et al., 2003).

Este projeto representa os primeiros passos do nosso grupo para avaliar o papel de p53 no efeito antitumoral de IFN $\beta$. Com as ferramentas desenvolvidas aqui, pretendemos elucidar mais informações sobre o efeito funcional de IFN $\beta$ mais p53 na inibição de proliferação celular ou indução de morte celular. Se a combinação de IFN $\beta$ mais p53 se mostrar interessante, pretendemos avaliar os genes alvos que são ativados nestas vias. Acreditamos que tratamentos que tem como alvo a combinação das vias p53 e IFN $\beta$ podem ser interessantes para inibição de melanoma. 


\section{CONCLUSÃO}

\subsection{Knock-down de p53 na linhagem B16 via miRNA}

Para o knock-down de p53 foi utilizada a tecnologia de RNAi em células B16, com os resultados obtidos através de Western e ensaios de luciferase, pudermos verificar que a redução de p53 nas linhagens celulares B16-LMP-p53 ocorreu de maneira satisfatória mesmo quando as células foram tratadas com doxorrubicina.

\subsection{Construção e caracterização de vetores plasmidiais (pcDNA3) portadores dos cDNAs para eGFP, Luciferase, p53 e IFN $\beta$}

A tecnologia de clonagem Gateway é uma plataforma universal que permite inserir o seu gene de interesse em vários sistemas de expressão. Para construção dos vetores plasmidiais o vetor de "entrada" pENTR foi construído inserindo os genes de interesse, luciferase, eGFP, p53 e IFN $\beta$ por clonagem tradicional, utilizando-se enzimas de restrição. Em seguida foi verificado se o inserto estava presente assim como se a orientação estava correta através de mapas de restrição. Para a construção dos vetores cDNA, os vetores pENTR foram inseridos no vetor pcDNA/V5-DEST por meio de recombinação homóloga, esta fase foi realizada com sucesso com exceção do pcDNALuciferase.

A caracterização destes vetores foi realizada para verificar a expressão dos transgenes. No caso do pcDNAeGFP foi realizado ensaio de citômetro de fluxo e ensaio de ELISA para os vetores pcDNAp53 e pcDNAIFN 3 . Como mostram nossos resultados, os vetores com eGFP e IFN $\beta$ apresentaram expressão do transgene. Ensaios de ELISA para o pcDNAp53 ainda estão em andamento. 


\subsection{Construção e caracterização de vetores adenovirais (AdCMV) portadores dos cDNAs para eGFP, Luciferase, p53 e IFN $\beta$}

Assim como os vetores de destino pcDNA, os vetores pAdCMV também foram recombinados, com sucesso, com os vetores $p E N T R$. Para isso, os vetores $p E N T R$ foram recombinados com o vetor pAdCMV/V5-DEST, gerando pAdCMV-p53, pAdCMV-IFN $\beta$, pAdCMV-eGFP e pAdCMV-luciferase. A confirmação da recombinação foi feito por mapeamento com enzimas de restrição.

Para verificar a expressão do transgene pAdCMVeGFP foi realizado um ensaio de citômetro de fluxo que validou a construção mostrando expressão forte de GFP. Para os vetores com p53 e IFN $\beta$ estamos realizando ensaios de ELISA para caracterizar essas construções.

\subsection{Ensaios para explorar possíveis interações entre as vias de p53 e IFN $\beta$, incluindo ensaios repórter e de ciclo celular}

Com os vetores plasmidiais abordamos um primeiro ensaio exploratório de interações entre p53 e IFN $\beta$ através da ativação de promotores alvos destas vias. Como mostrado em nossos resultados, o vetor de p53 e IFN $\beta$ independentemente ativaram seus promotores, pPGTx $\beta$-Luc e pIFN $\beta$-Luc respectivamente, demonstrando assim que os vetores construídos apresentam e expressam seus transgenes, validando dessa forma a construção. No entanto a combinação do p53 e IFN $\beta$ não apresentou uma indução do promotor, maior do que a dos vetores sozinhos. 


\section{REFERÊNCIAS BIBLIOGRÁFICAS}

ALIZADEH, H.; HOWARD, K.; MELLON, J.; MAYHEW, E.; RUSCIANO, D.; NIEDERKORN, J. Y. Reduction of liver metastasis of intraocular melanoma by interferon-beta gene transfer. Invest. Ophthalmol. Vis. Sci., v. 44, p. 3042-3051, 2003.

BAJGELMAN, M. C.; COSTANZI-STRAUSS, E.; STRAUSS, B. E. Exploration of critical parameters for transient retrovirus production. J. Biotechnol., v. 103, p. 97-106, 2003.

BAJGELMAN, M. C.; STRAUSS, B. E. Development of an adenoviral vector with robust expression driven by p53. Virology, v. 371, p. 8-13, 2008.

BENJAMIN, C. L.; ANANTHASWAMY, H. N. p53 and the pathogenesis of skin cancer. Toxicol. Appl. Pharmacol., v. 224, p. 241-248, 2007.

BOX, N. F.; TERZIAN, T. The role of p53 in pigmentation, tanning and melanoma. Pigment Cell Melanoma Res., v. 21, p. 525-533, 2008.

CHAWLA-SARKAR, M.; LINDNER, D. J.; LIU, Y. F.; WILLIAMS, B. R.; SEN, G. C.; SILVERMAN, R. H.; BORDEN, E. C. Apoptosis and interferons: role of interferon-stimulated genes as mediators of apoptosis. Apoptosis, v. 8, p. 237-249, 2003.

CHIOCCA, E. A.; SMITH, K. M.; MCKINNEY, B.; PALMER, C. A.; ROSENFELD, S.; LILLEHEI, K.; HAMILTON, A.; DEMASTERS, B. K.; JUDY, K.; KIRN, D. A phase I trial of Ad.hIFN- $\beta$ gene therapy for glioma. Mol. Ther., v. 16, n. 3, p. 618-626, 2008.

DE PALMA, M.; MAZZIERI, R.; POLITI, L. S.; PUCCI, F.; ZONARI, E.; SITIA, G.; MAZZOLENI, S.; MOI, D.; VENNERI, M. A.; INDRACCOLO, S.; FALINI, A.; GUIDOTTI, L. G.; GALLI, R.; NALDINI, L. Tumor-targeted interferon- $\alpha$ delivery by Tie2-expressing monocytes inhibits tumor growth and metastasis. Cancer Cell, v. 14, p. 299-311, 2008.

DICKINS, R. A.; HEMANN, M. T.; ZILFOU, J. T.; SIMPSON, D. R.; IBARRA, I.; HANNON, G. J.; LOWE, S. W. Probing tumor phenotypes using stable and regulated synthetic microRNA precursors. Nat. Genet., v. 37, p. 1289-1295, 2005.

DITTMER, D.; PATI, S.; ZAMBETTI, G.; CHU, S.; TERESKY, A. K.; MOORE, M.; FINLAY, C.; LEVINE, A. J. Gain of function mutations in p53. Nat. Genet., v. 4, p. 42-46, 1993.

EBERLE, J.; FECKER, L. F.; HOSSINI, A. M.; KURBANOV, B. M.; FECHNER, H. Apoptosis pathways and oncolytic adenoviral vectors: promising targets and tools to overcome therapy resistance of malignant melanoma. Exp. Dermatol., v. 17, p. 1-11, 2008.

\footnotetext{
De acordo com:

ASSOCIAÇÃO BRASILEIRA DE NORMAS TÉCNICAS. NBR 6023: Informação e documentação: referências: elaboração. Rio de Janeiro, 2002.
} 
EL-DEIRY, W. S.; KERN, S. E.; PIETENPOL, J. A.; KINZLER, K. W.; VOGELSTEIN, B. Definition of a consensus binding site for p53. Nat. Genet., v. 1, p. 45-49, 1992.

FUNK, W. D.; PAK, D. T.; KARAS, R. H.; WRIGHT, W. E.; SHAY, J. W. A transcriptionally active DNAbinding site for human p53 protein complexes. Mol. Cell. Biol., v. 12, p. 2866-2871, 1992.

GIGLIA-MARI, G.; SARASIN, A. TP53 mutations in human skin cancers. Hum. Mutat., v. 21, p. 217228, 2003.

HA, L.; MERLINO, G.; SVIDERSKAYA, E. V. Melanomagenesis: overcoming the barrier of melanocyte senescence. Cell Cycle, v. 7, n. 13, p. 1944-1948, 2008.

HOLLSTEIN, M.; RICE, K.; GREENBLATT, M. S.; SOUSSI, T.; FUCHS, R.; SORLIE, T.; HOVIG, E.; SMITH-SORENSEN, B.; MONTESANO, R.; HARRIS, C. C. Database of p53 gene somatic mutations in human tumors and cell lines. Nucleic Acids Res., v. 22, p. 3551-3555, 1994.

HSIAO, M.; LOW, J.; DORN, E.; KU, D.; PATTENGALE, P.; YEARGIN, J.; HAAS, M. Gain-of-function mutations of the p53 gene induce lymphohematopoietic metastatic potential and tissue invasiveness.

Am. J. Pathol., v. 145, p. 702-714, 1994.

HU, G.; MANCL, M. E.; BARNES, B. J. Signaling through IFN regulatory factor-5 sensitizes p53deficient tumors to DNA damage-induced apoptosis and cell death. Cancer Res., v. 65, p. 7403-7412, 2005.

JAMES, C. D.; HE, J.; CARLBOM, E.; NORDENSKJOLD, M.; CAVENEE, W. K.; COLLINS, V. P. Chromosome 9 deletion mapping reveals interferon alpha and interferon beta-1 gene deletions in human glial tumors. Cancer Res., v. 51, p. 1684-1688, 1991.

KAVANAGH, D.; HILL, A. D.; DJIKSTRA, B.; KENNELLY, R.; MCDERMOTT, E. M.; O'HIGGINS, N. J. Adjuvant therapies in the treatment of stage II and III malignant melanoma. Surgeon, v. 3, p. 245-256, 2005.

KERN, S. E.; KINZLER, K. W.; BRUSKIN, A.; JAROSZ, D.; FRIEDMAN, P.; PRIVES, C.; VOGELSTEIN, B. Identification of p53 as a sequence-specific DNA-binding protein. Science, v. 252, p. 1708-1711, 1991.

KERN, S. E.; PIETENPOL, J. A.; THIAGALINGAM, S.; SEYMOUR, A.; KINZLER, K. W.; VOGELSTEIN, B. Oncogenic forms of p53 inhibit p53-regulated gene expression. Science, v. 256, p. 827-830, 1992.

LENS, M. B.; DAWES, M. Global perspectives of contemporary epidemiological trends of cutaneous malignant melanoma. Br. J. Dermatol., v. 150, p. 179-185, 2004.

LEVINE, A. J. p53, the cellular gatekeeper for growth and division. Cell, v. 88, p. 323-331, 1997.

LOWE, S. W.; RULEY, H. E. Stabilization of the p53 tumor suppressor is induced by adenovirus 5 E1A and accompanies apoptosis. Genes Dev., v. 7, p. 535-545, 1993. 
LOWE, S. W.; RULEY, H. E.; JACKS, T.; HOUSMAN, D. E. p53-dependent apoptosis modulates the cytotoxicity of anticancer agents. Cell, v. 74, p. 957-967, 1993a.

LOWE, S. W.; SCHMITT, E. M.; SMITH, S. W.; OSBORNE, B. A.; JACKS, T. p53 is required for radiation-induced apoptosis in mouse thymocytes. Nature, v. 362, p. 847-849, 1993b.

LU, R.; AU, W. C.; YEOW, W. S.; HAGEMAN, N.; PITHA, P. M. Regulation of the promoter activity of interferon regulatory factor-7 gene. Activation by interferon snd silencing by hypermethylation. J. Biol. Chem., v. 275, p. 31805-31812, 2000.

LU, W.; FIDLER, I. J.; DONG, Z. Eradication of primary murine fibrosarcomas and induction of systemic immunity by adenovirus-mediated interferon beta gene therapy. Cancer Res., v. 59, p. 52025208, 1999.

MIYAKOSHI, J.; DOBLER, K. D.; ALLALUNIS-TURNER, J.; MCKEAN, J. D.; PETRUK, K.; ALLEN, P. B.; ARONYK, K. N.; WEIR, B.; HUYSER-WIERENGA, D.; FULTON, D. Absence of IFNA and IFNB genes from human malignant glioma cell lines and lack of correlation with cellular sensitivity to interferons. Cancer Res., v. 50, p. 278-283, 1990.

MORI, T.; ANAZAWA, Y.; IIIZUMI, M.; FUKUDA, S.; NAKAMURA, Y.; ARAKAWA, H. Identification of the interferon regulatory factor 5 gene (IRF-5) as a direct target for p53. Oncogene, v. 21, p. 29142918, 2002.

NYBERG-HOFFMAN, C.; SHABRAM, P.; LI, W.; GIROUX, D.; AGUILAR-CORDOVA, E. Sensitivity and reproducibility in adenoviral infectious titer determination. Nat. Med., v. 3, p. 808-811, 1997.

PORTA, C.; HADJ-SLIMANE, R.; NEJMEDDINE, M.; PAMPIN, M.; TOVEY, M. G.; ESPERT, L.; ALVAREZ, S.; CHELBI-ALIX, M. K. Interferons alpha and gamma induce p53-dependent and p53independent apoptosis, respectively. Oncogene, v. 24, p. 605-615, 2005.

REN, Z.; YE, X.; FANG, C.; LU, Q.; ZHAO, Y.; LIU, F.; LIANG, M.; HU, F.; CHEN, H. Intratumor injection of oncolytic adenovirus expressing HSP70 prolonged survival in melanoma B16 bearing mice by enhanced immune response. Cancer Biol. Ther., v. 7, n. 2, p. 191-195, 2008.

ROY-CHOWDHURY, J.; HORWITZ, M. S. Evolution of adenoviruses as gene therapy vectors. Mol. Ther., v. 5, p. 340-344, 2002.

RUSSELL, W. C. Update on adenovirus and its vectors. J. Gen. Virol., v. 81, p. 2573-2604, 2000.

SABEL, M. S.; SONDAK, V. K. Pros and cons of adjuvant interferon in the treatment of melanoma. Oncologist, v. 8, p. 451-458, 2003.

SANDOVAL, R.; XUE, J.; PILKINTON, M.; SALVI, D.; KIYOKAWA, H.; COLAMONICI, O. R. Different requirements for the cytostatic and apoptotic effects of type I interferons. Induction of apoptosis requires ARF but not p53 in osteosarcoma cell lines. J. Biol. Chem., v. 279, p. 32275-32280, 2004. 
SATO, M.; TANIGUCHI, T.; TANAKA, N. The interferon system and interferon regulatory factor transcription factors -- studies from gene knockout mice. Cytokine Growth Factor Rev., v. 12, p. 133142, 2001.

SERVANT, M. J.; GRANDVAUX, N.; TENOEVER, B. R.; DUGUAY, D.; LIN, R.; HISCOTT, J. Identification of the minimal phosphoacceptor site required for in vivo activation of interferon regulatory factor 3 in response to virus and double-stranded RNA. J. Biol. Chem., v. 278, p. 9441-9447, 2003.

SHARPLESS, E.; CHIN, L. The INK4a/ARF locus and melanoma. Oncogene, v. 22, p. 3092-3098, 2003.

STERMAN, D. H.; RECIO, A.; CARROLL, R. G.; GILLESPIE, C. T.; HAAS, A.; VACHANI, A.; KAPOOR, V.; SUN, J.; HODINKA, R.; BROWN, J. L.; CORBLEY, M. J.; PARR, M.; HO, M.; PASTAN, I.; MACHUZAK, M.; BENEDICT, W.; ZHANG, X.; LORD, E. M.; LITZKY, L. A.; HEITJAN, D. F.; JUNE, C. H.; KAISER, L. R.; VONDERHEIDE, R. H.; ALBELDA, S. M. A phase I clinical trial of single-dose intrapleural IFN- $\beta$ gene transfer for malignant pleural mesothelioma and metastatic pleural effusions: high rate of antitumor immune responses. Clin. Cancer Res., v. 13, p. 4456-4466, 2007.

STRAUSS, B. E.; BAJGELMAN, M. C.; COSTANZI-STRAUSS, E. A novel gene transfer strategy that combines promoter and transgene activities for improved tumor cell inhibition. Cancer Gene Ther., v. 12, p. 935-946, 2005.

STRAUSS, B. E.; HAAS, M. The region $3^{\prime}$ to the major transcriptional start site of the MDR1 downstream promoter mediates activation by a subset of mutant P53 proteins. Biochem. Biophys. Res. Commun., v. 217, p. 333-340, 1995.

TAKAOKA, A.; HAYAKAWA, S.; YANAI, H.; STOIBER, D.; NEGISHI, H.; KIKUCHI, H.; SASAKI, S.; IMAI, K.; SHIBUE, T.; HONDA, K.; TANIGUCHI, T. Integration of interferon-alpha/beta signalling to p53 responses in tumour suppression and antiviral defence. Nature, v. 424, p. 516-523, 2003.

YOSHIDA, J.; MIZUNO, M.; FUJII, M.; KAJITA, Y.; NAKAHARA, N.; HATANO, M.; SAITO, R.; NOBAYASHI, M.; WAKABAYASHI, T. Human gene therapy for malignant gliomas (glioblastoma multiforme and anaplastic astrocytoma) by in vivo transduction with human interferon beta gene using cationic liposomes. Hum. Gene Ther., v. 15, p. 77-86, 2004.

WAKABAYASHI, T.; NATSUME, A.; HASHIZUME, Y.; FUJII, M.; MIZUNO, M.; YOSHIDA, J. A phase I clinical trial of interferon-beta gene therapy for high-grade glioma: novel findings from gene expression profiling and autopsy. J. Gene Med., v. 10, p. 329-339, 2008. 